\title{
قراءة في تعريف علم البيان
}

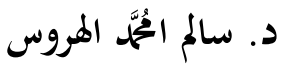

كلية الآداب - جامعة مصراتة

\section{مقدمة:}

الحمد لله خلق الإنسان علمه البيان، والصلاة والسلام على أفصح العرب، القائل:

(( إن من البيان لسحرا )(1)، وعلى آله وصحبه أئمة الهدى والتبيان، وبعد فقد دأبنا في دراسة إلها

البلاغة العربية بالمراحل الدراسية المختلفة بما فيها المرحلة الجامعية، على التلقي والتسليم، وهو ما اضطرنا إلى الاعتماد على الحفظ؛ إذ لم يكن يغرس فينا التأمل فيما ندرسه من الشواهد، أو تحليله، ناهيك عن المناقشة أو الحوار الذي يفضي إلى اقامنا بالتعجيز. بيد أنني -في ضوء تكرار المقررات الدراسية في البلاغة من خلال المذكرات الموسومة بـ"المنهاج الواضح للبلاغة" التي ألفها الأستاذ حامد عوني للمرحلة الثانوية بالمعاهد الزهريةكنت أشعر بالهوة بين تعريف علم البيان من حيث مفهومه النظري، وما يؤول إليه في طرح مباحثه تأصيلا وتفسيرا. إن هذا الشعور كان وراء هذه القراءة التي تمدف إلى محاولة الإجابة عن الأسئلة التالية، أو -على الأقل- بث روح المراجعة الجادة فيما تطرحه من إشكاليات، وهي: هل اتفق البلاغيون على الطرح الذي اقترحه السكاكي "ت 626هـ" بحسب ما آل إليه عند الخطيب القزويني "ت 739هـ" في "تلخيص المفتاح"؟ وما مدى صحة أن يكون المعنى واحدا والطرق مختلفة؟ بمعنى هل يمكن أن تتناوب أساليب التشبيه، والاستعارة بأنواعها، والمجاز المرسل، والمجاز 1- الجامع الصحيح: ثُحَّ بن إسماعيل البخاري، باب: إن من البيان لسحرا، رقم الحديث "5767"، 
العقلي، والكناية بحرية تامة دونما نظر إلى السياقات الخاصة، أو الفروق بين الأساليب؟ ولتحقيق

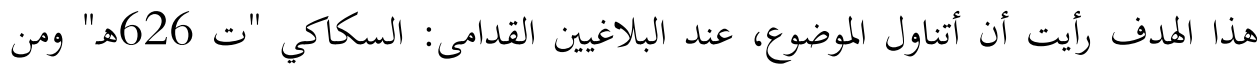
بعده ضمن كتاب شروح التلخيص، ثم البلاغيين المحدثين ضمن كتابين: أحدهما: التعبير البياني،

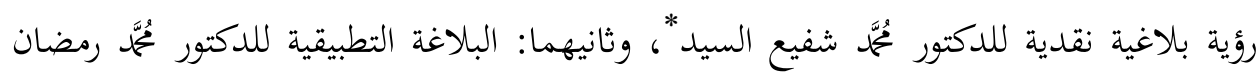
الجربي **، ثم أختم البحث بتعقيب على ما تناولته.

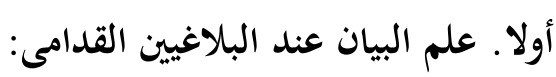

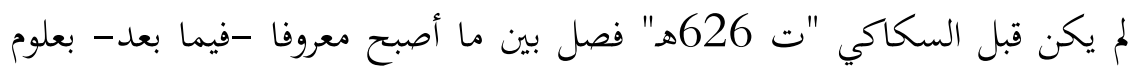
البلاغة العربية الثلاثة: (المعاني، البيان، البديع)؛ فقد كانت المصطلحات:البيان، والفصاحة،

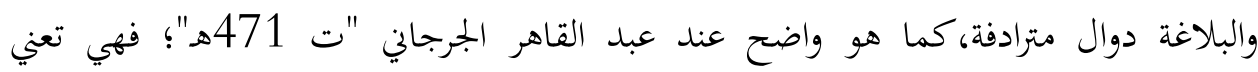

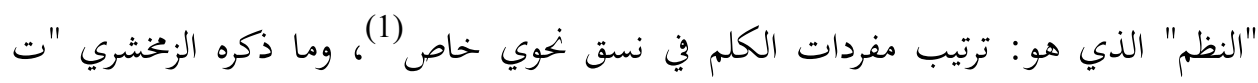

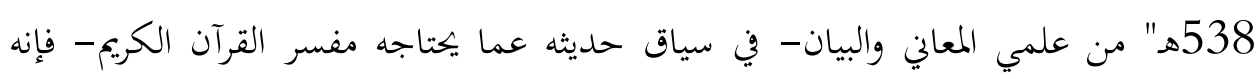

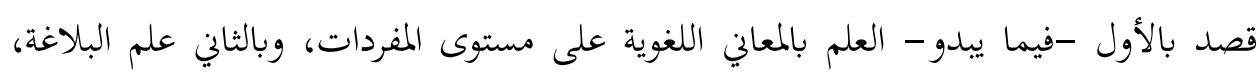
والدليل على ذلك أنه أدرج "الالتفات" في علم البيان(2)، كما أن من البلاغيين من لم يلتزم

* أستاذ البلاغة والأسلوبية، كلية دار العلوم، جامعة القاهرة، له مؤلفات عدة، منها: الاتخاه الأسلوبي في النقد ** أستاذ البلاغة والنقد في الجامعة الأسمرية، حقق كتاب جامع العبارات في تحقيق الاستعارات لمؤلفه أممد

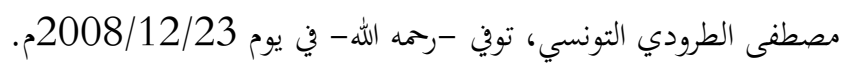

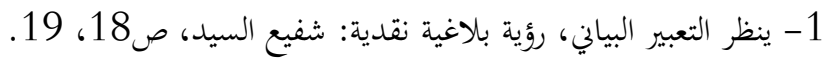

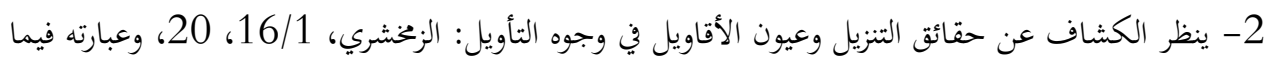

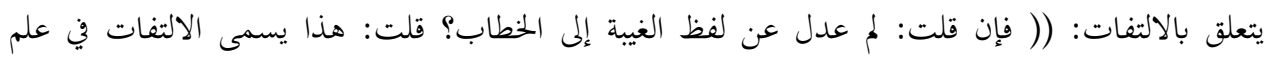

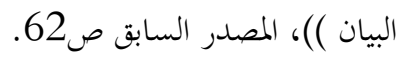


بمشروع السكاكي (1) فقد ذكر القزويني "ت 739هـ" أن كثيرا من الناس يسمي الجميع "علم

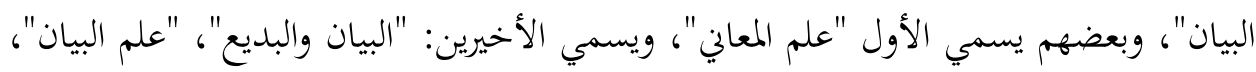
وبعضهم يسمي الجميع: "علم البديع"(2). وحسب الفصل بين العلوم الثلاثة فإن أول ما يتبادر إلى الذهن -بعد تحديدها- هو العلاقة بين هذه العلوم؛ فقد ناقش البلاغيون المتأخرون ترتب علم البيان على علم المعاني، وانتهى بكم الحال إلى أها علاقة مفرد بمركب، وأن مراعاة علم البيان لا تتم إلا بعد رعاية المطابقة، وإذا كانت المطابقة لا تتم إلا بعد رعاية الفصاحة، فإن علم البيان مرتبط بالفصاحة

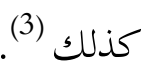
وطبقا لما آل إليه الأمر من الفصل بين هذه العلوم، كان لزاما على السكاكي "ت

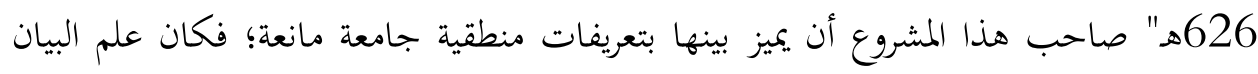

1- لقد قسم السكاكي كتابه (مفتاح العلوم) إلى ثلاثة أقسام: خص الأول منها لعلم الصرف، والثاني لعلم

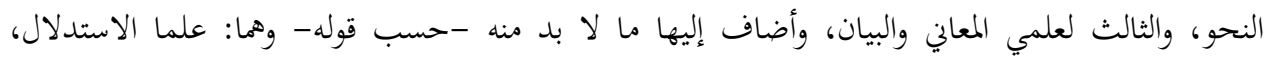

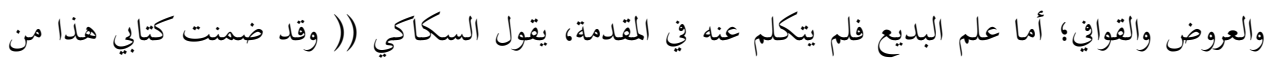

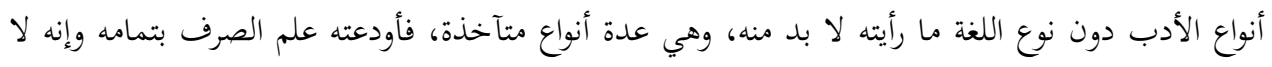

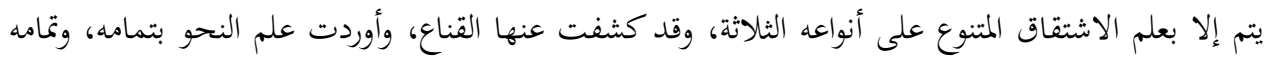

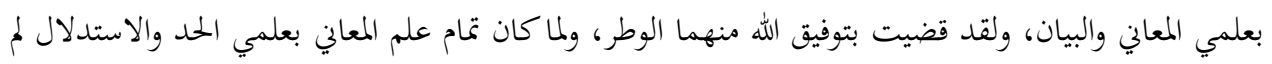

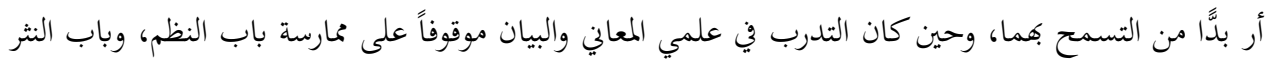

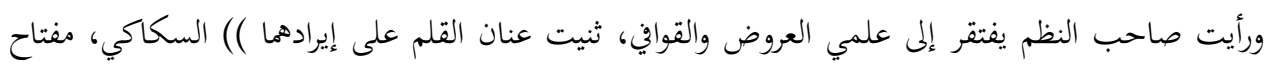

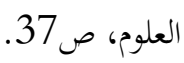
2- الإيضاح في علوم البلاغة: الخطيب القزويني، قدم له، وبوبه، وشرحه: علي بو ملحم، منشورات دار ومكتبة

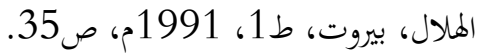

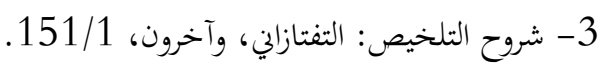


هو: (( معرفة إيراد المعنى الواحد في طرق وتراكيب مختلفة بالزيادة ليحترز بالوقوف على ذلك عن الخطإ في مطابقة الكلام لتمام المراد منه ذلك )() (1). بيد أن التعريف الذي اشتهر بين البلاغيين -وهو المستهدف في هذا البحث- تعريف الخطيب القزويني "ت 739هـ"، وهو: (( علم يعرف به إيراد المعنى الواحد بطرق مختلفة في لئ وضوح الدلالة عليه )(2). إن مما اتفق عليه البلاغيون -في هذا السياق - أن المراد بـ"العلم" -هنا- الملكة، أو

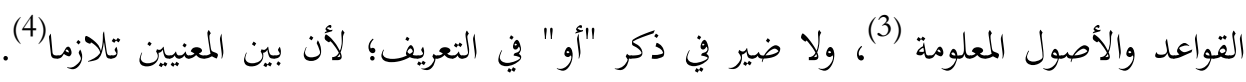
والمراد بالمعنى الواحد هو: كل معنى يدخل تحت قصد المتكلم؛ ف"اللام" في "المعنى" للاستغراق العرين (5) المراد بالمعن أما الطرق المختلفة في وضوح الدلالة على المعنى المقصود فهي الأساليب التي يصح فيها التفاوت، وهي ذات العلاقة الدلالية العقلية التي لا تخرج عن دلالة التضمن أو دلالة الالتزام؛ وإنما أدرج التشبيه في مباحثه لابتناء الاستعارة عليه (6). ولتوضيح فكرة إيراد المعنى الواحد بطرق مختلفة يورد البلاغيون مثالا يستدل به -إلى

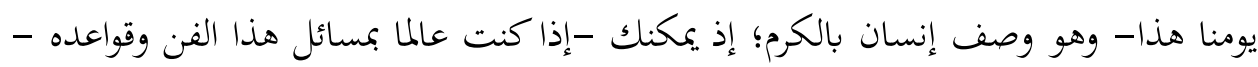
على حد قول البلاغيين- أن تتحدث عنه بأحد أساليب التشبيه -وهي متنوعة- فتقول: "عُمَّم

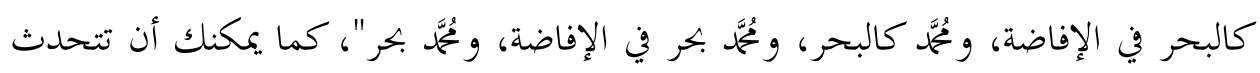

$$
\begin{aligned}
& \text { 1- 1 - مفتاح العلوم، ص249. } \\
& \text { 2- الإيضاح، ص187. } \\
& \text { 3- ينظر شروح التلخيص، 258/3، 257، الإناح، صل 257. }
\end{aligned}
$$

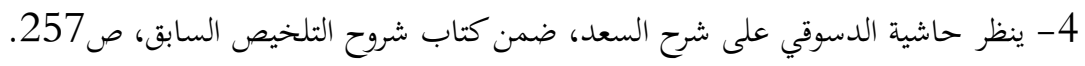

5- شروح التلخيص، 258/3.

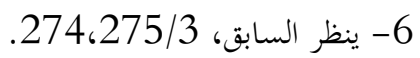


عن هذا المعنى "الغرض" بأسلوب من أساليب الاستعارة؛ فتقول: زرت بحرا، وغمر مُجمّم بفضله

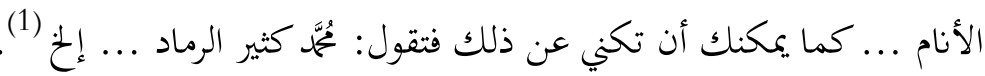

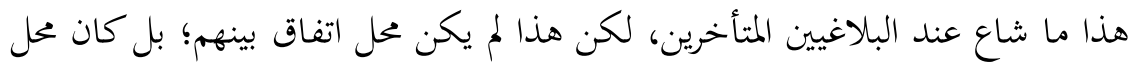

نقاش لبعضهم ومراجعة من عدة وجوه:

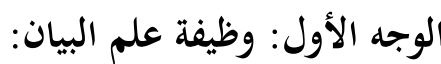

إن التعريف ينص صراحة على أن علم البيان علم نتاج وإبداع، بمعنى أن من يتمكن البهن

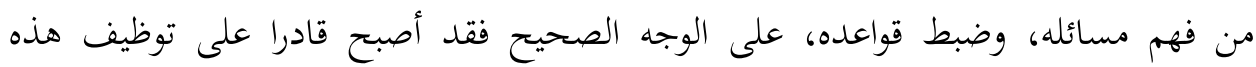

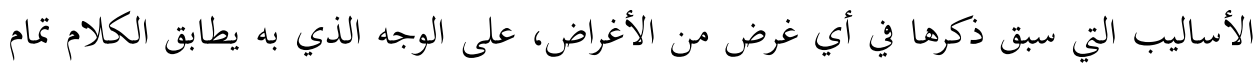

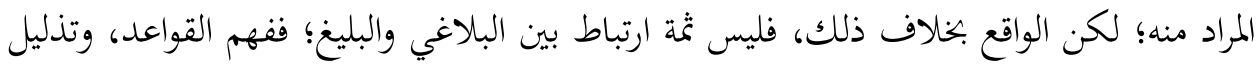

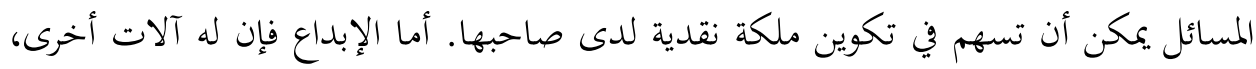

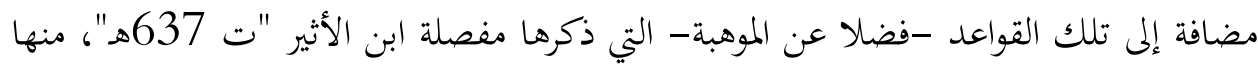
حفظ القرآن الكريم، وكثير من الأحاديث النبوية، والفصيح من المنثور والمنظوم (2).

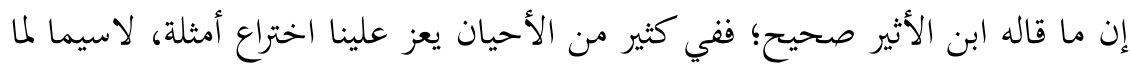
دق من الصور المركبة من التشبيه والاستعارة، وهي ما أطلق عليه علماء البلاغة بالخاصة الغريبة،

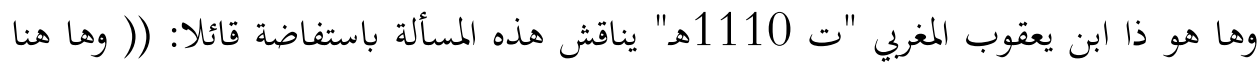
بحث، وهو أن ما ذكر من كون هذا الفن لما ذكرت فيه شروط المقبول من التشبيه، والمجاز، والكناية، وحقيقة كل منها، وأقسامه، كان في ذلك تنبيه على فائدته، وهو: أن يطلب من فن

$$
\text { 1- ينظر شروح التلخيص، ص ص259، } 260 .
$$

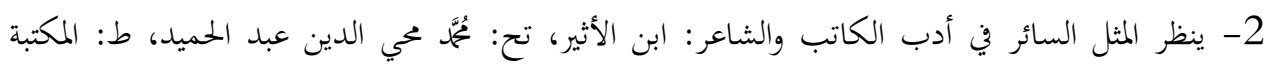

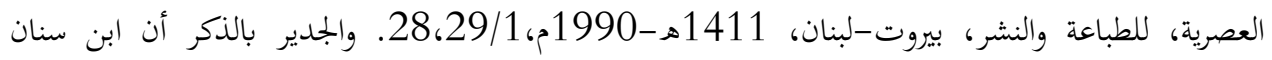

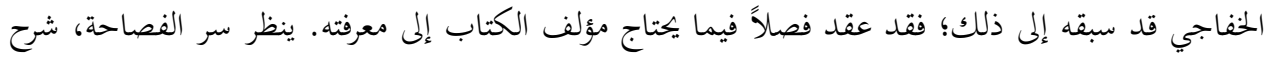

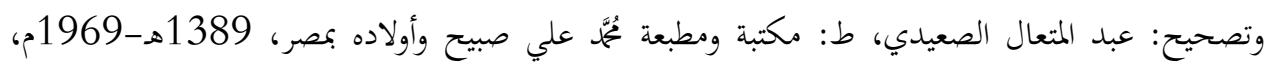
ص280-282. (280. 
تراكيب البلغاء، واستعمالات العرب ما وقع؛ ليقاس عليه غيره مما يراد استعماله، ويعرف المقبول

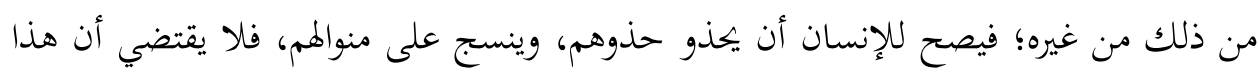

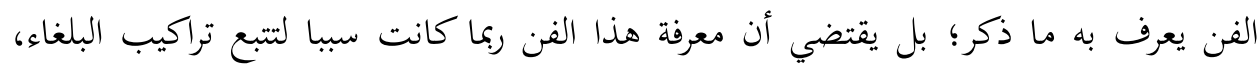
الذي يكصل العلم بكيفية الإيراد؛ إذ بمارسة ذلك يكتسب الإنسان قوة لاستعمال ما يريد كما يصنع البلغاء؛ فلا معنى لتعريفه بما ذكر؛ إذ هو تعريف بلازم غير محقق اللزوم خفي ... وإن أريد

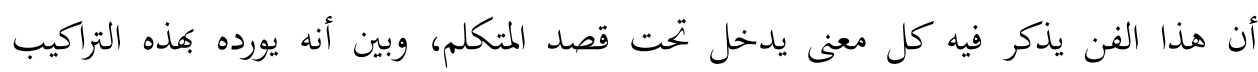

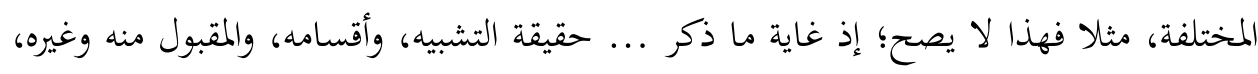
وكذا المجاز والكناية ... ليحترز بذلك عن التعقيد المعنوي الذي يشتمل عليه غير المقبول، وهذا البحث لم يظهر جوابه بعد، فليتأمل )(1). نقلت هذا النص -على طوله- لأنه يعكس عمق الثفكير لدى ابن يعقوب؛ ذلك بأنه

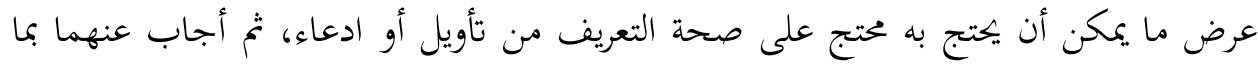
فيه غنى لكل منصف.

ولئن كان هذا التعمق في البحث لم يتجاوز إدراك المشكل إلى حل المشكل، كما نص

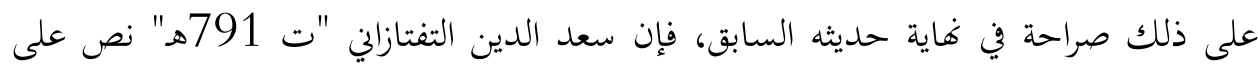
المشكل واقتراح حله، وإن كان في سياق آخر يتمثل في علاقة التشبيه بعلم البيان قائلا: (( فإن إنسان قلت: إذا كان ذكر التشبيه في علم البيان بسبب ابتناء الاستعارة عليه، فلم جعل مقصودا برأسه دون أن يجعل مقدمة لبحث الاستعارة؟ قلت: لأنه لكثرة مباحثه، وجموم فوائده، ارتفع عن أن سئن يجعل مقدمة لبحث الاستعارة، واستحق أن يجعل أصلا برأسه. هذا هو الكلام في شرح مقدمة 1- مواهب الفتاح في شرح تلخيص المفتاح: ابن يعقوب المغربي، ضمن كتاب شروح التلخيص، 261/3، 
"علم البيان" على ما اخترعه السكاكي، وأنت خبير بما فيه من الاضطراب، والأقرب أن يقال: علم البيان: علم يبحث فيه عن التشبيه، والمجاز والكناية، ثم يشتغل بتفصيل هذه المباحث من

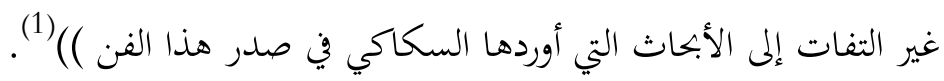
إن نظرة التفتازاين "ت 791 هـ" هذه تحدف إلى الخروج من مأزق فكرة المعنى الواحد، والتعبير عنه بأساليب مختلفة، وكذلك التخلص من عدم مطابقة التعريف لختويات التهات علم البيان، وقد أشار إلى ذلك بقوله: "ثم يشتغل بتفصيل ذلك (أساليب التشبيه والمجاز والكناية) من غير التاليف التفات إلى الأبحاث علاقة علوم البلاغة ببعضها ...".

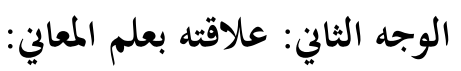

إن من يقرأ كتب البلاغيين المؤلفة وفق مدرسة شراح التلخيص يدرك أنها تلتزم الترتيب التماني

على هذا النحو: مقدمة في الفصاحة والبلاغة، علم المعاني، علم البيان، علم البديع (2).

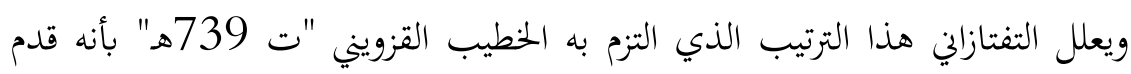

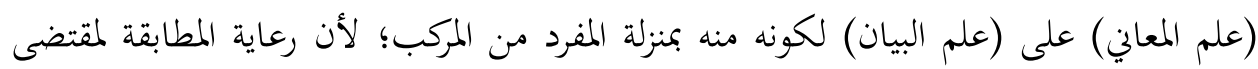

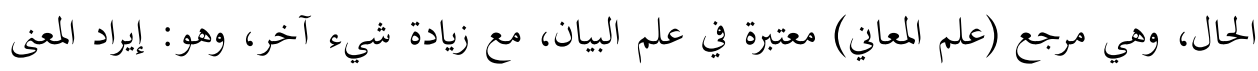

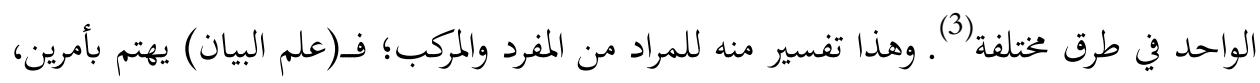

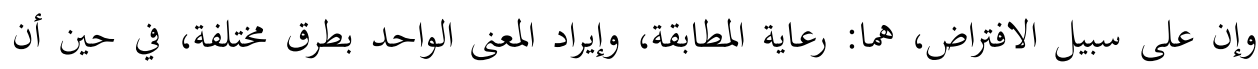
(علم المعاني) يهتم برعاية المطابقة، وإن كان على سبيل الافتراض كذلك.

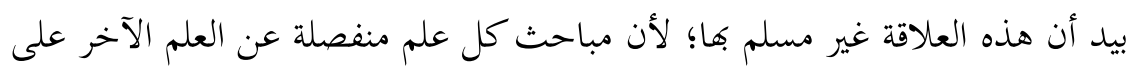

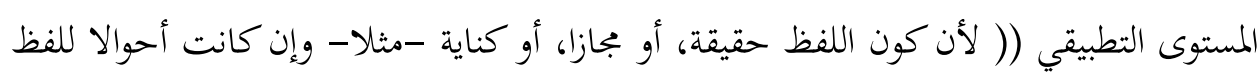

1- المطول في شرح تلخيص المفتاح: سعد الدين التفتازاني، نشر المكتبة الأزهرية للتراث، "د. تت" ص309،

$$
\text { 2- 2 ينظر شروح التلخيص، مثلا. }
$$

3- ينظر غتصر السعد، ضمن شروح التلخيص، 152/1، ينال 153. 
قد يقتضيها الحال؛ لكن لا يبحث عنها في (علم البيان) من حيث إنه يطابق بها اللفظ مقتضى

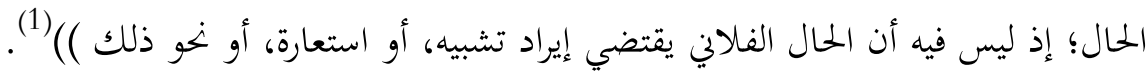

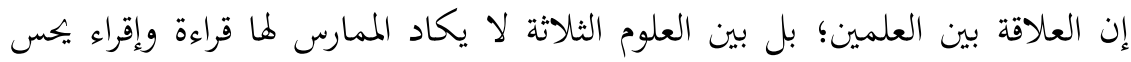
كها، من حيث المباحث والموضوعات التي تشتمل عليها؛ فـ(( الحق الذي لا ينازع فيه منصف

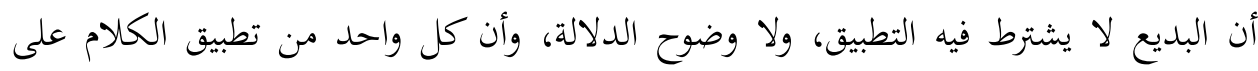
مقتضى الحال، ومن الإيراد بطرق مختلفة، ومن وجوه التحسين، قد يوجد دون الآخرين، وأول

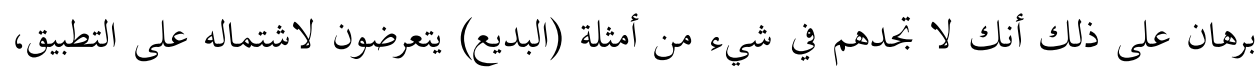
والإيراد، بل بتحد كثيرا منها خاليا من التشبيه، والاستعارة، والكناية التي هي طرق لئ علم البيان. هذا هو الإنصاف وإن كان مخالفا لكامام الأكثرين ()(2). صحيح قد نستحضر علمي المعاني والبديع في علم البيان وذلك عندما نقوم بتحليل صورة فنية تحليلا بلاغيا، فقد يجتمع في التشبيه الاحتباك، أو التتميم، أو الحذف، أو الإطناب، أو المطابقة، وهذه كلها تثري الصورة الفنية، وتحولها من مبتذلة عامة، إلى خاصة غريبة لا ينشئها إلا المفلقون السحرة من أرباب الفصاحة والبلاغة. ومثل هذه العلاقة تبرز عند عبد القاهر الجرجاني "ت 471هـ" في حديثه عن النظم، وأنه المعول عليه في التفريق بين كلام وآخر، وبين استعارة وأخرى؛ إن الاستعارة تتحول من العامي المبتذل إلى الخاصي الغريب الذي لا بحده إلا في كلام الفحول، ولا يقوى عليه إلا أفراد الرجال كقول الشاعر(3) - (3) أَخذْنا بأطرافِ الََْحاديثِ بيننا .

$$
\text { 1- المطول في شرح تلخيص المفتاح، ص35. }
$$

2- عروس الأفراح في شرح تلخيص المفتاح: بهاء الدين السبكي، ضمن صند كتاب شروح التلخيص 284/3.

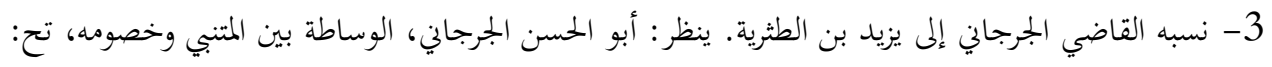

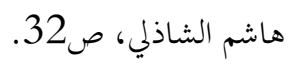


فليست الغرابة في عقد مقارنة بين السير السريع السلس، والسيلان فذلك شبه معروف ولكن

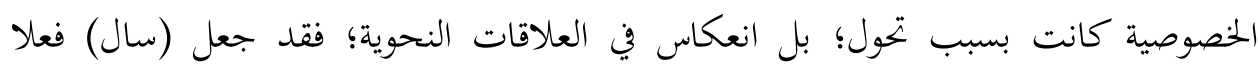

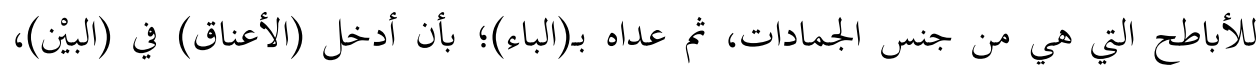

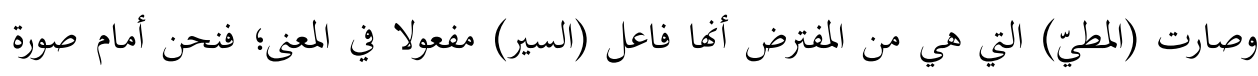

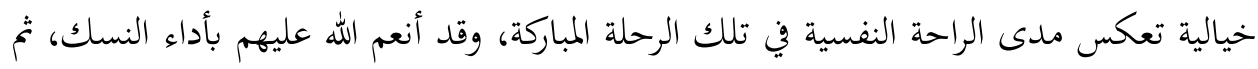

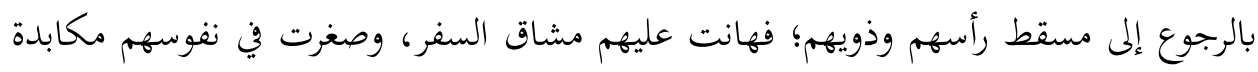
الطريق؛ لذلك لو قال: "سالت المطي في الأباطح" لم يكن شيئا (1). ثانياً. علم البيان عند البلاغيين المحدثين:

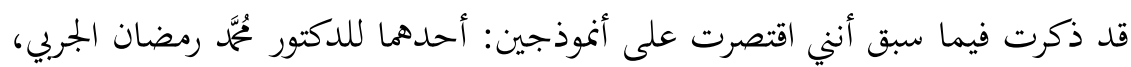

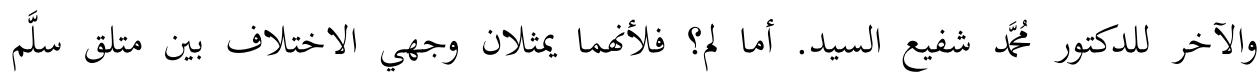

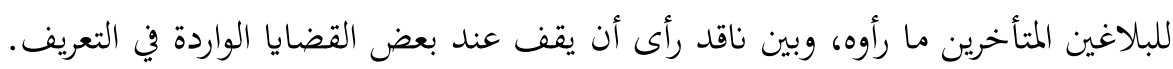

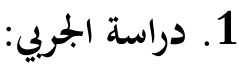

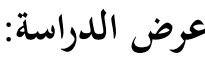

إن أول ما يسجل للجربي من إيجابيات أنه بدأ بذكر نماذج شعرية على عادة طرق

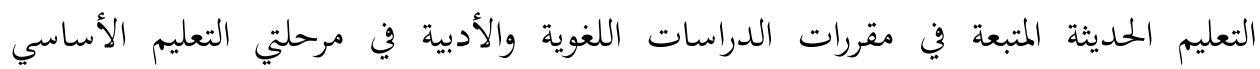

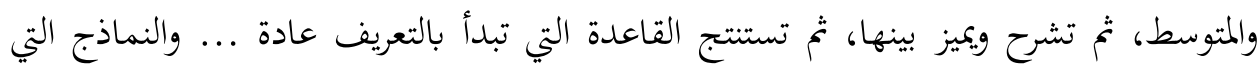

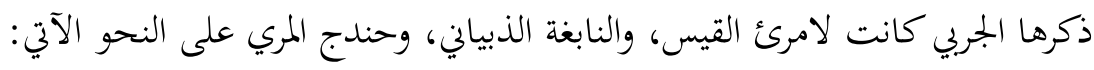
علم البيان: قال امرؤ القيس في وصف الليل بالطول:

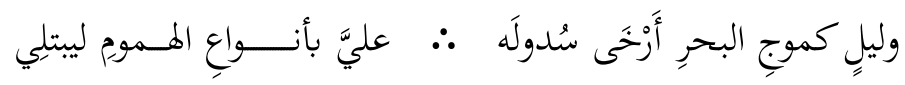

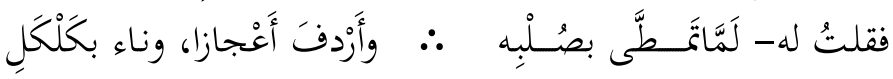

1- ينظر دلائل الإعجاز: عبد القاهر الجرحاني، قرأه وعلق عليه معمود شاكر، ط3، دار المدني بحدة،

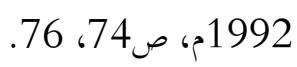




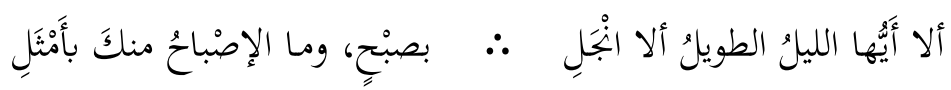

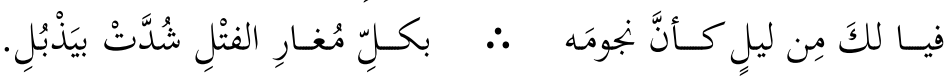

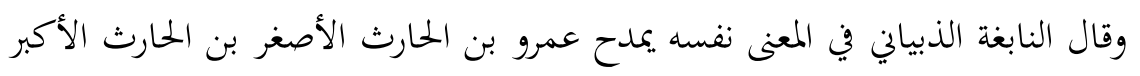

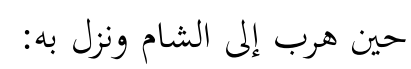

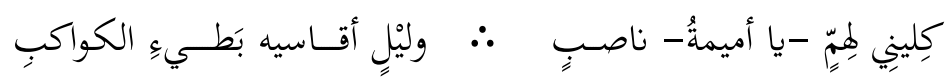

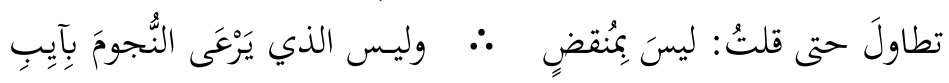

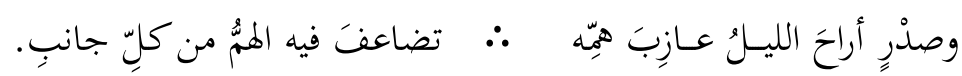

وقال حندج المري في وصف ليل (صول) بالطول:

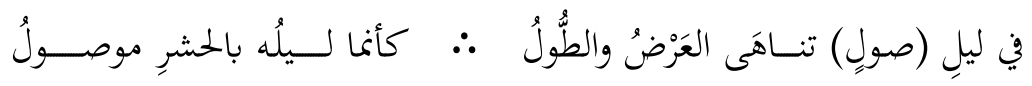

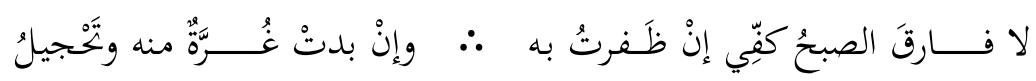

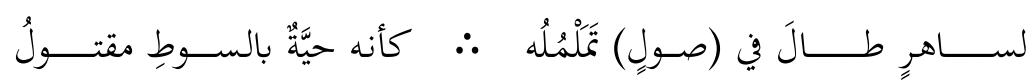

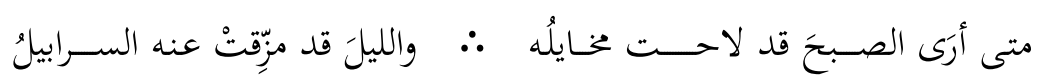

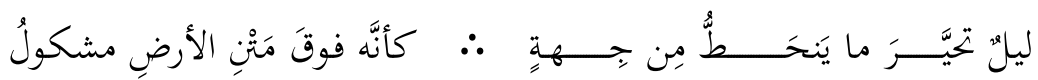

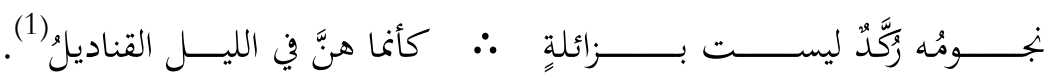

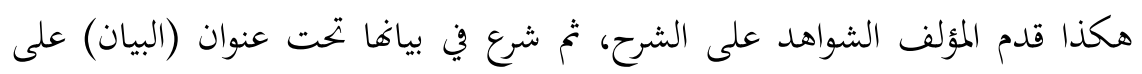
النحو التالي:

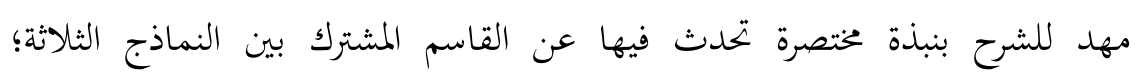

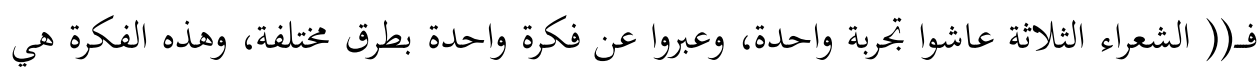

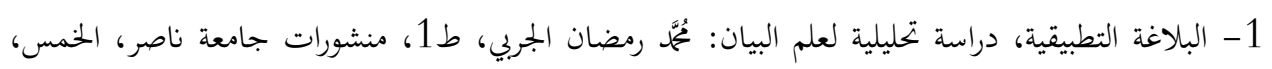

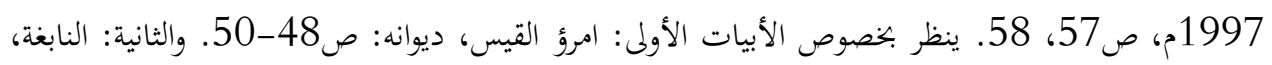

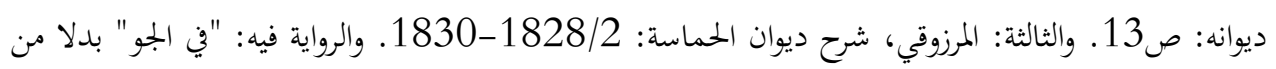
"الليل". 
وصف الليل بالطول، وما يلقاه ساهره فيه من الهموم والألم )(1)، ثم بدأ يتتبع النماذج أنموذجا أنموذجا، ثم بيتا بيتا بطريقة يغلب عليها توضيح ما اشتملت عليه من ظواهر بلاغية: (تشبيه،

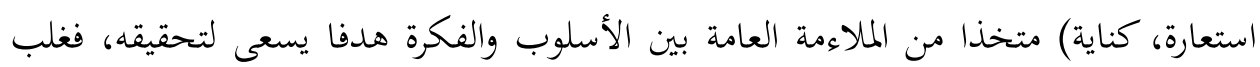
عليه الأسلوب الإنشائي المكتظ بنعوت المبالغة؛ (( فامرؤ القيس ضاق ذرعا بطول الليل، وامتلأت نفسه بالهموم وقد صور ذلك الضيق أدق تصوير؛ فقال: ورب ليال كثيرة طال ليله،

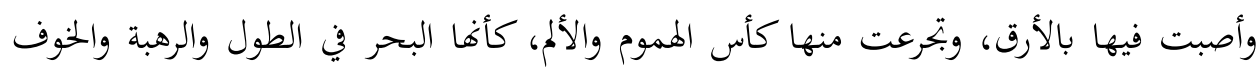

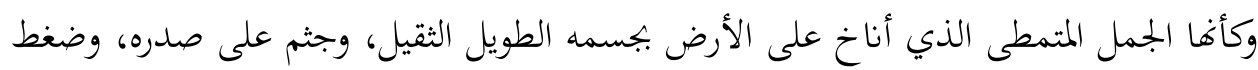
عليه بكل ثقله حتى كادت نفسه أن تزهق، ولذا تمنى زوال الليل، وظهور ضوء الصباح؛ لتستريح نفسه، ولكنه التفت إلى نفسه وأوضح بأن همومه مستمرة ليلا ووهارا.

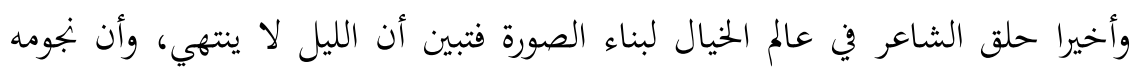

ثابتة لا تتحرك كأها ربطت بحبال متينة محكمة الفتل، وشدت بجبل (يذبل) الراسخ )) (2). أما تتبع النماذج بيتا بيتا فقد كان على النحو التالي: ففي البيت الأول تشبيه تتثيلي رائع حيث شبه طول الليل وما يحدثه من ألم، وضيق على قلب ساهره، شبهه بأمواج البحر في الطول والتتابع وعدم الانتهاء والفزع وشدة الخوف ... . . 1. وفي البيت الثاني استعارة مكنية، حيث شبه الليل في طوله وثقله على قلب ساهره بجمل ثقيل الجسم له صلب يزداد طولا بتمطيه، وله أعجاز ومؤخرة وله صدر ... وهذا بحسيم للمعاني لتشاهد ماثلة أمام العيون، وتشخيص للجمادات، فصارت ناطقة ... . 2. وفي البيت الثالث كناية عن صفة، هي الضيق من طول الليل، والحيرة مستمرة ليلا 
3. وفي البيت الرابع كناية عن صفة، وهي طول الليل، والكناية موحية ومؤثرة؛ لأهما

دعوى مؤيدة بالدليل؛ فالليل لا ينتهي لأن نجومه ثابتة لا تتزحزح.

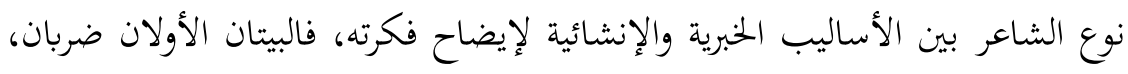

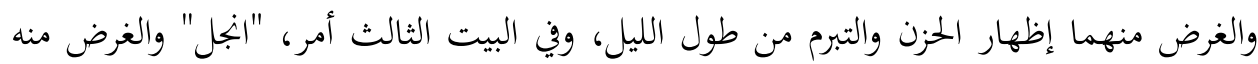

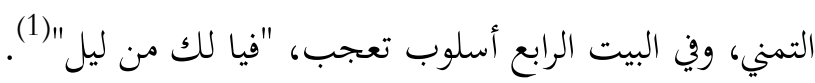

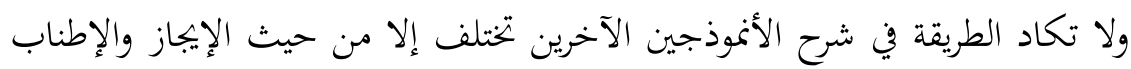
في كل منهما؛ ففي صورة النابغة وصف لليل الطويل، وما يعيشه الشاعر فيه من المموم، وقد عبر الشاعر عن ذلك مستخدما أسلوب الاستعارة حين صور الصبح بالراعي الغائب الذي لئي لايعود، وصور النجوم الثابتة بالإبل السارحة.

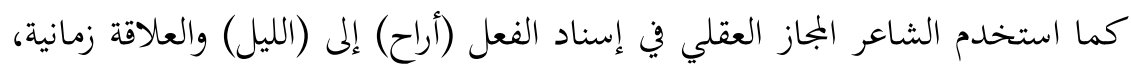
والكناية في قوله: "تضاعف فيه الحزن من كل جانب" عن شدة الضيق والألم (2). أما في صورة (حندج) فإن الشاعر قد فصل القول ونوع الصور فالليل ... وصل غايته ومنتهاه في الطول، والشاعر متشوق لرؤية الصبح؛ لترتاح نفسه، ولكنه في حيرة وقلق نفسي؛ لأنه شاك في مجيئه كما توحي بذلك كلمة (إن) ... والتشبيه بالحية المقتولة بالسوط ... وفي البيت الرابع أتى بالاستفهام لاستبطائه رؤية الصباح. ويرافق ذلك كله تشخيص لليل بشيء مشرق مغطى بسرابيل، وملابس سود، وقد استبطأ الشاعر تمزق هذه الملابس المظلمة حتى يشرق النور من جنباتا الممزقة على سبيل الاستعارة المكنية الموحية المؤثرة في المشاعر، كما شخصه في صورة إنسان متحير في أمره (3)، تم يختم هذه الشروح بعنوان (القاعدة) وهي تشتمل على نتيجتين، وموازنة كما يأتي:

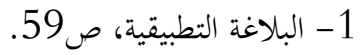

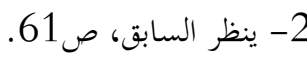

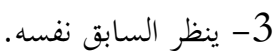


1. تعريف علم البيان - كما هو عند الخطيب القزويني- هو: علم يعرف به إيراد المعنى

الواحد بطرق مختلفة في وضوح الدلالة عليه.

2. وصف البياني: وهو الذي يعبر عن الفكرة الواحدة بأساليب متعددة لغرض وضوح

العبارة، وبيان الفكرة المطلوبة، بحيث تكون الدلالة واضحة مرة، وأوضح مرة ثانية، وأكثر وضوحا لهن

مرة ثالثة (1)

\section{الموازنة: n- na}

هؤلاء الشعراء الثلاثة ... عبروا جميعا عن فكرة واحدة، وهي وصف الليل بالطول، وما يقاسيه فيه ساهره من الضيق النفسي، والآلام الجسمية، والوحشة، غير أن أسلوب النابغة كان

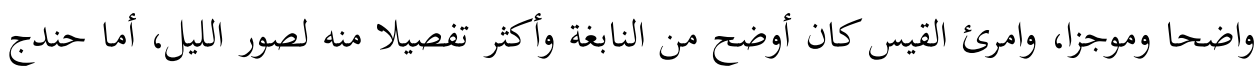

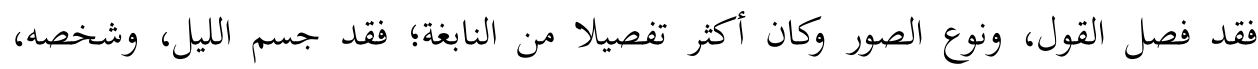

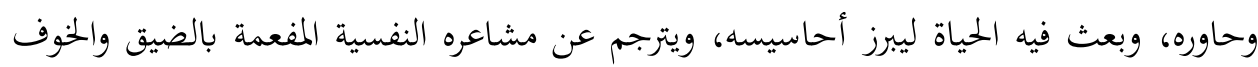

من الليل (2)

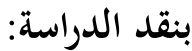

إن هذا الصنيع -في اعتقادي- يفتقد المنهج العلمي في المقارنة بين الأساليب؛ لأنه لم يحدد بالدقة تمايزها، فقد اكتفى بالتعميم، كما أنه ابتعد عن رؤية البلاغيين ومقارناقم بين الأساليب، فهم افترضوا أن المعنى الواحد يمكن أن يعبر عنه بأسلوب التشبيه بأنواعه المختلفة

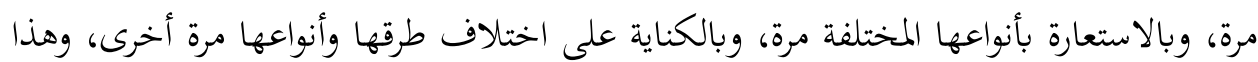
ما لم يفعله الجربي؛ بل إن الشواهد نفسها لا تحقق ذلك، فقد عبر امرؤ القيس عن فكرته بالأساليب الثلاثة فجمع بين أساليب التشبيه والاستعارة والكناية، فقد شبه (الليل) أولا بـ(موج البحر) في تتابعه، وعدم انقضائه، وظلمته، ثم جسمه عن طريق الاستعارة في صورة (جمل) تتمدد كل أجزائه، لكن هذا (الجمل) يتحول إلى إنسان عاقل بفعل الخطاب الذي وجهابه

$$
\text { 2- 1- البلاغة التطبيقية، ص62. }
$$


الشاعر له، وهذا الخطاب تعالت نبرته، وتحول إلى صرخة غاضب يئس من الحياة، وتشاءم من

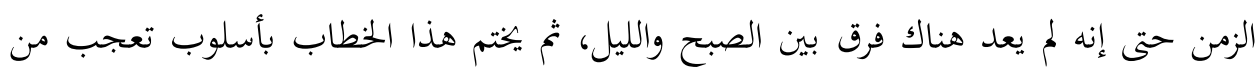

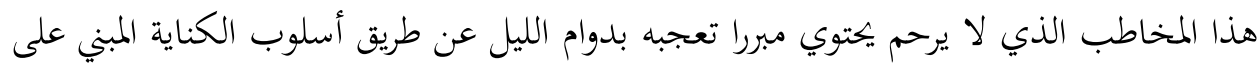
أسلوب التشبيه، أو التخيل والظن حسب اختلاف العلماء في إفادة (كأن) ذلك إذا كان خبرها

مشتقام(1)

ولو سلمنا بأن امرأ القيس يمكن أن تكون صورته هذه أنموذجا صالحاً للأساليب

الثلاثة: التشبيه، الاستعارة، الكناية، فإن ثمة فرقا بينها في التفاصيل، يجعل منها أساليب لا تلتفول في معانيها؛ فإذا كان في تشبيه (الليل) بـ(موج البحر) ما يفيد التتابع والفزع وعدم الانقضاء،

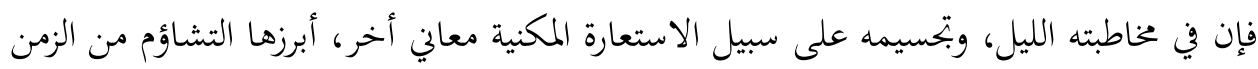
الذي يرمز إليه استدعاء صفات الإبل؛ فحمله على تلك الصرخة الانفعالية التي يعكسها

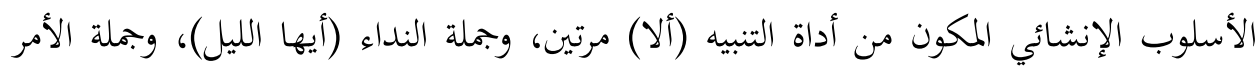
(انجل)، لكنه لم يقف عند هذا الحد؛ بل أعقبه بالجملة التذييلية: (وما الإصباح منك بأمثل) المؤكدة لمعنى التشاؤم، الذي يدل عليه استواء الليل والنهار في حياة الشاعر.

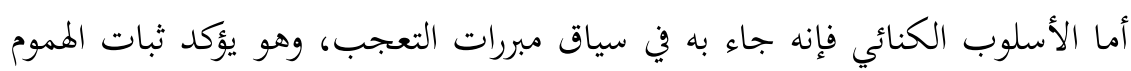
بثبات زماها ومعنى هذا المعنى أن امرأ القيس متشائم في صورته الشعرية من الحياة، ومتبرم من فئس الزمن، وفاقد للأمل حتى مما فيه أمل. وإذا التفتنا إلى صورة النابغة، فإن أول ما لفت انتباهي أن الصورة خالية من أسلوب

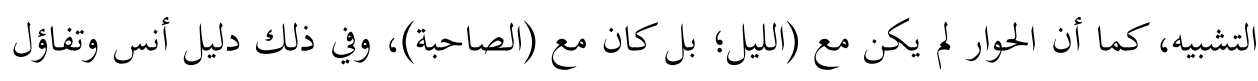
"كليني لهم يا أميمة ناصب"، و (الليل) ليس مصدر قلق للشاعر؛ بل هو جزء من مكون ثلاثي - كما يدل على ذلك العطف- يضم الهم، والليل الطويل، والصدر، لكنه جزء مهم؛ فهو الذي مئل أعاد الهموم الغابرة إلى صدر الشاعر، ويظهر التمايز جليا في أن النابغة كان يرجو الصباح 1- ينظر مغني الليبيب عن كتب الأعاريب: ابن هشام الأنصاري، تح: مازن المبارك ومُحّمّ علي حمد الله، ط2، دار الفكر، 1969م، 209/1. 
و يأنس به، وإن أبطأ؛ فليله: "بطيء الكواكب" والبطء لا يعني الثبات كما هو الحال عند امرئ

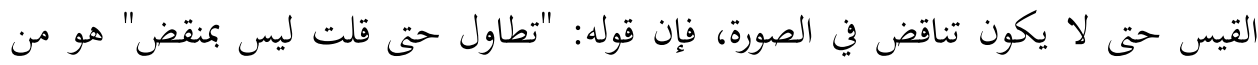

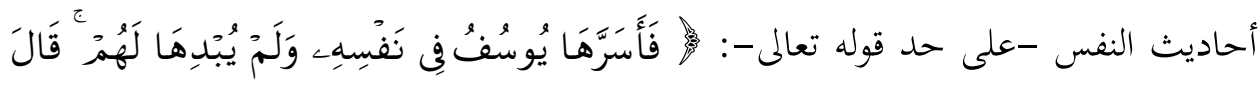

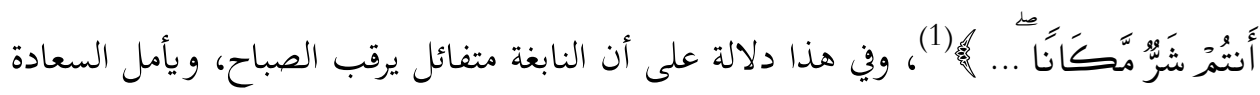

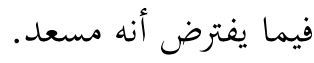

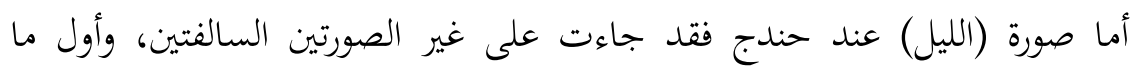

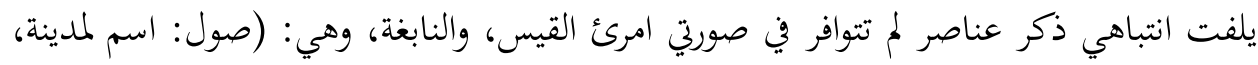

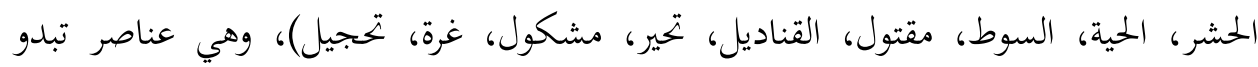
متنافرة ومضطربة، فضلا عن تكرار أسلوب الشك والمقاربة (كأن وخبرها المشتق في جملتين)؛

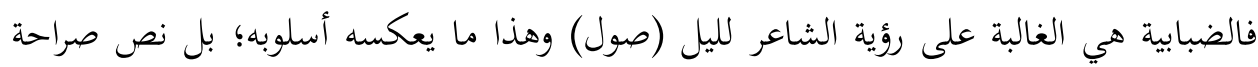

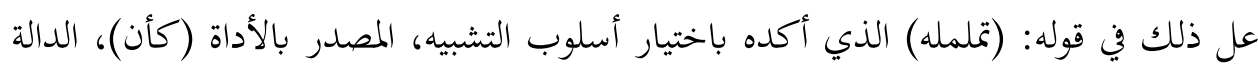
على قوة الاتحاد بين الطرفين فهو لا يختلف عن الحية التي قتلت بالسوط.

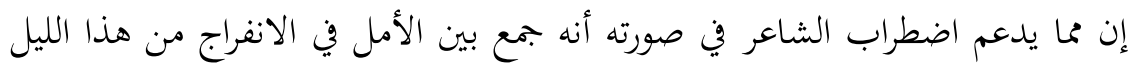

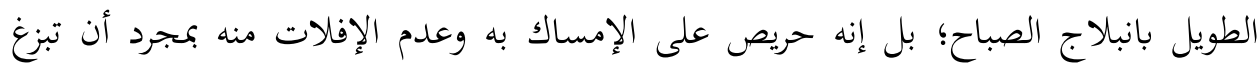

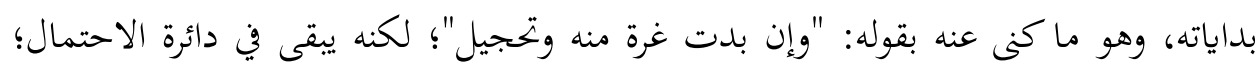

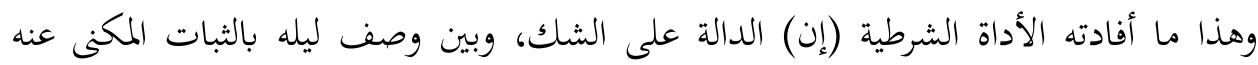
بقوله: "نجومه ركد ليست بزائلة"، فضلا عن أن هذا الليل صوره مظلما حينا، وهو ما دل التل عليه قوله -في سياق الاستفهام الاستبطائي-: "والليل قد مزقت عنه السرابيل"، وصوره متلألئا مزدانا بالنجوم حينا آخر، وهو ما دل عليه قوله: "كأثما هن في الليل القناديل".

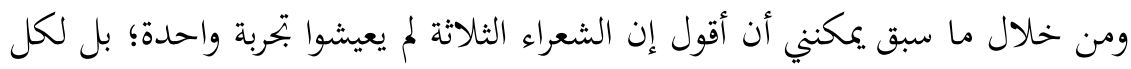
منهم تحربته في الحياة؛ فامرؤ القيس متشائم، والنابغة متفائل، وحندج بين التفاؤل والتشاؤم فهو

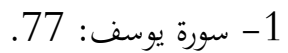


مضطرب، ويمكن أن يكون سببه تقليد الصورتين السابقتين.كما أنه يمكني أن أخلص -وأنا مطمئن- إلى أن اللغة الأدبية لا يككن أن تقبل مثل هذه السطحية في التحليل، التي تمدر

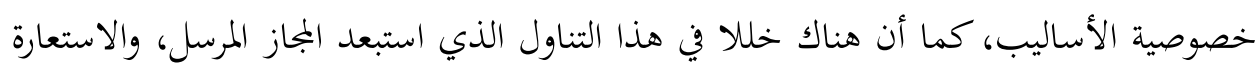
التمثيلية.

\section{ثانيا: دراسة شفيع السيد:}

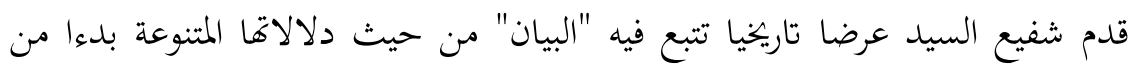

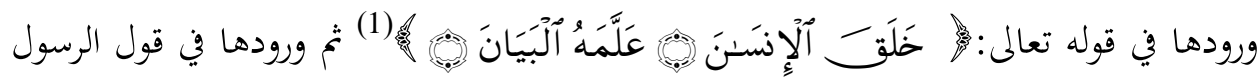
عند الجاحظ في مواطن متعددة؛ بل المساواة بينها وبين البلاغة والفصاحة.

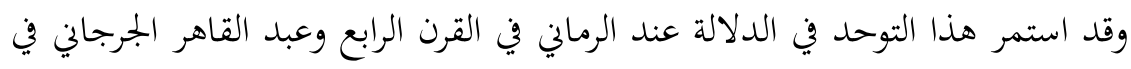

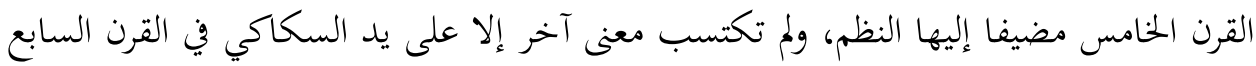

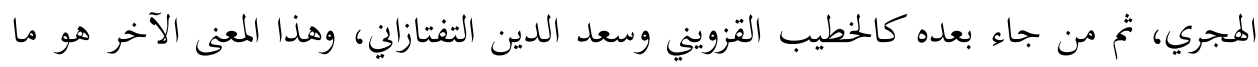

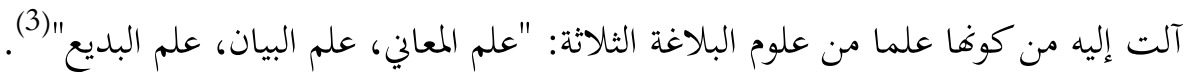

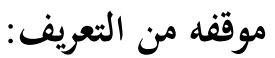

يككن أن نلخص موقفه من التعريف فيما يلي:

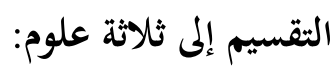

اعترض على هذا التقسبم؛ لأن اقتصار علم البيان على دراسة التشبيه والمجاز والكناية،

لا معنى له؛ فالظواهر البلاغية الأخرى الموزعة في الفرعين الآخرين، هي ظواهر بيانية كذلك (4).

$$
\begin{aligned}
& \text { 1- - س سورة الرمن: 3، } 4 . \\
& \text { 2- الجامع الصحيح: رقم الحديث (15) (5767)، 138/7. }
\end{aligned}
$$

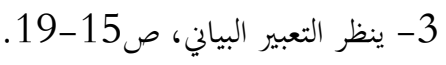

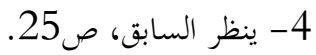




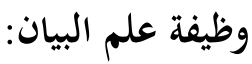

بعد التسليم بهذا التصنيف الذي صنفه السكاكي وتلاميذه باعتباره أمرا واقعا يتوقف

$$
\text { شفيع السيد وقفات متنوعة تعنى بجزئيات في تعريف علم البيان. }
$$

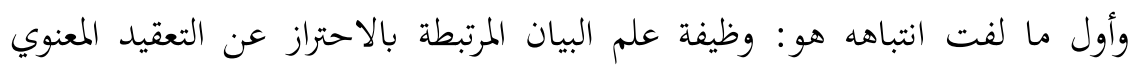

الذي هو شرط من شروط الفصاحة، التي هي شرط من شروط البلاغة، فقد ناقش شفيعُ السيد الخطيب القزويني الذي برر انحصار البلاغة في العلوم الثلاثة السابقة بأن (( مرجعها (البلاغة) إلى الاحتراز عن الخطأ في تأدية المعنى المراد، وإلى تمييز الكلام الفصيح من غيره، والثاني -أعني

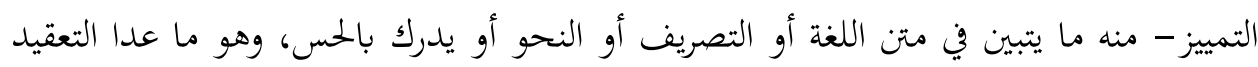

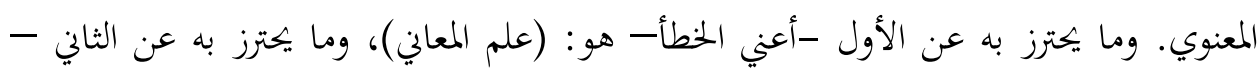
أعني التعقيد المعنوي- هو: (علم البيان)، وما يعرف به وجه تحسين الكلام بعد رعاية تطبيقه

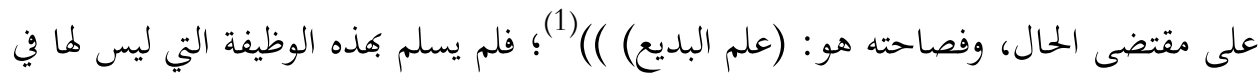
محتويات (علم البيان) أي ذكر، أو وجود؛ فـ((علم البيان لا يقدم إحصاء بكل الاستعمالات المجازية والكنائية البعيدة عن الغموض، كما لا يقدم معيارا منضبطا تقاس به تلك له

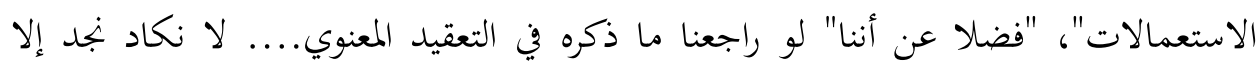
مثالا واحدا يتيما تناقله الدارسون من بعده، وذلك قول العباس بن الأحنف:

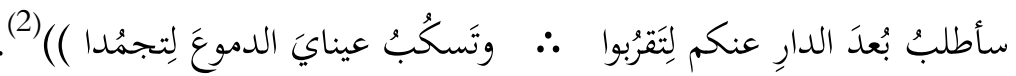

\section{مبحث الدلالة: - n}

يجرص البلاغيون على عرض يتعلق بتقديم دراسة حول أنواع الدلالات: (وضعية،

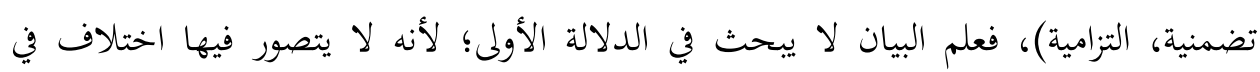

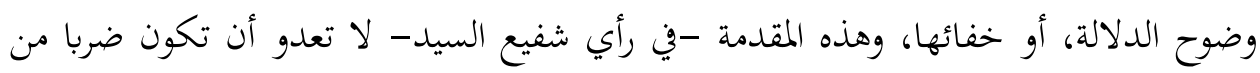

$$
\text { 1 - الإيضاح، ص35. }
$$

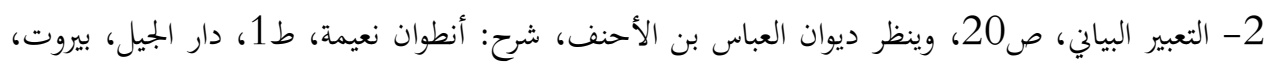
1416هـ-1995م، ص168. 
النضج الثقافي لعلم يعد غريبا عن ججال الدراسة الذي يعنى بدراسة التعبير اللغوي دراسة جمالية، والدليل على ذلك أننا (( لا نكاد نجد إشارة لها في ثنايا الحديث عن أي أسلوب من بعني أساليب البيان ... وإذا صح الاعتداد بهما (التضمنية والالتزامية) في أسلوبي المجاز المرسل، والكناية فإنه لا أثر لأي منهما بالمعنى المنطقي في أسلوبي التشبيه والاستعارة؛ لأهما كثيرا ما يبنيان على

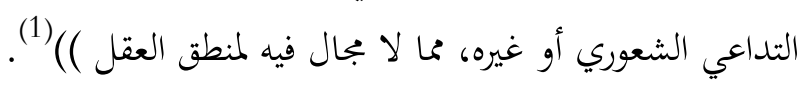

\section{إيراد المعنى الواحد بطرق مختلفة:}

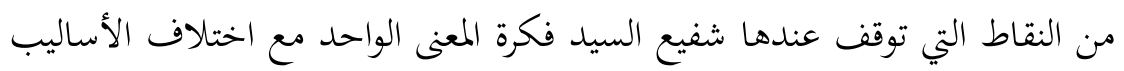

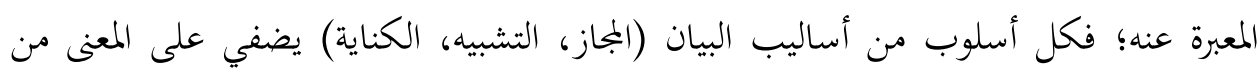

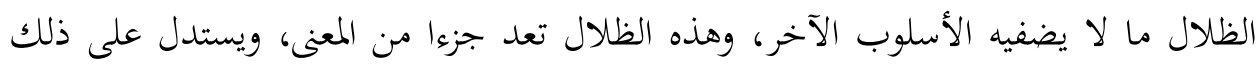
بتفريق عبد القاهر الجرجاني بين الجملتين تكونان من أسلوب بياني واحد اختلفا في الأداة؛

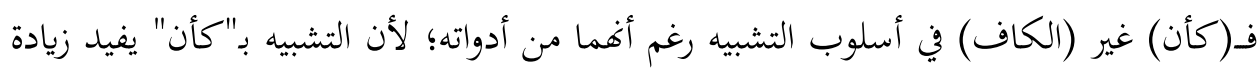
لم تكن في الأول ذلك بأن "كأن" تفيد قوة الاتحاد بين الطرفين، ويعقب على ذلك بقدئ الكوله:

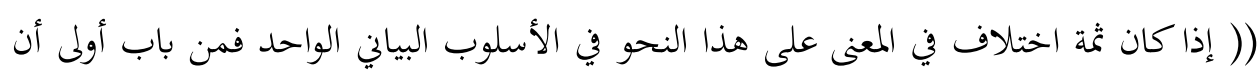
يكون هناك اختلاف في الدلالة بين أسلوبين مختلفين ()(2). كذلك توقف عند اختلاف الوضوح بين الطرق، فإذا كان البلاغيون رتبوا الوضوح بناء على الأساس المنطقي؛ فالتشبيه أوضح من الاستعارة، والاستعارة أوضح من الكناية، فإن شفيع بإِ السيد يرى أن الوضوح والخفاء (( يتوقف على طبيعة وجه الشبه بين الطرفين، وطبيعة الجهة

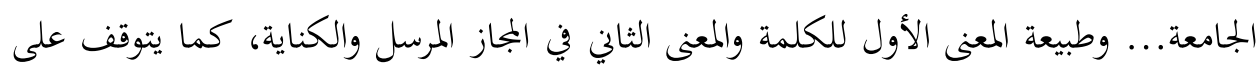
مدى ثقافة المتلقي، ولمح خياله، ودقة ملاحظته ... فما قد يكون واضحا لدى البعض يكون البكون

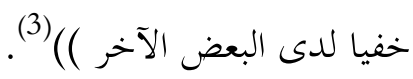

$$
\text { 2- 1- التعبير البياني، ص24. السابق، صابق، ص22. }
$$




\section{النتيجة:}

بعد تلك المناقشات المستفيضة التي أمعن فيها شفيع السيد توصل إلى: (( أن وظيفة

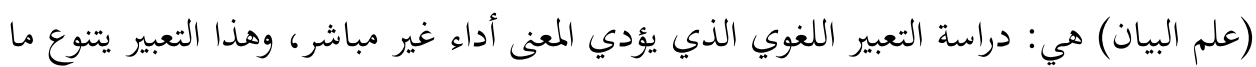

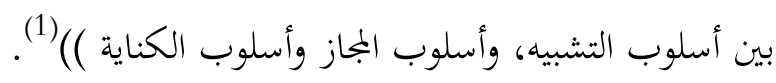

\section{موازنة وتعقيب: - n n}

إنني -بعد هذا العرض المختصر - يمكنني أن أقول إن المناقشات التي دارت بين

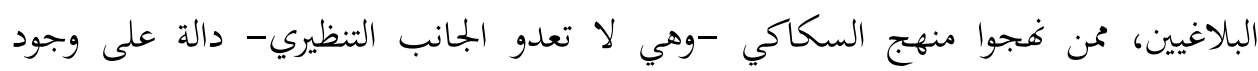

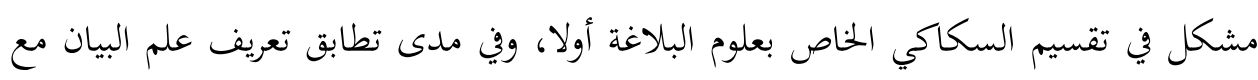

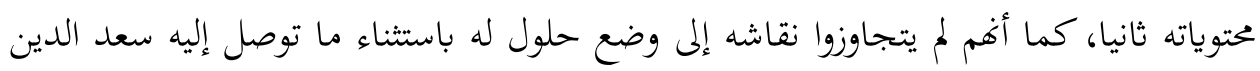

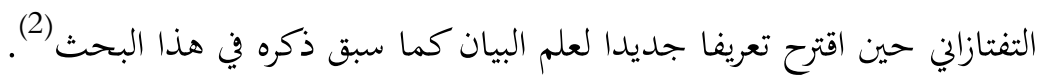

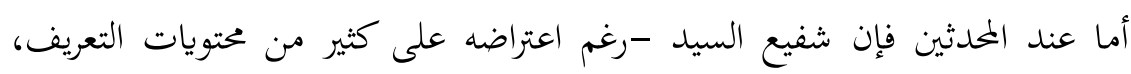

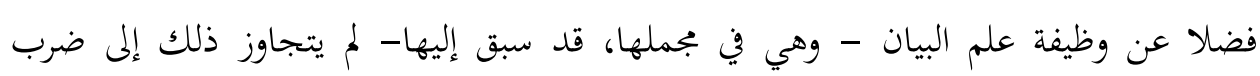
الأمثلة التي تؤيد ما يقول، بل اكتفى في تفنيد ما رآه الخطيب القزويني فيما يتعلق بوظيفة علم

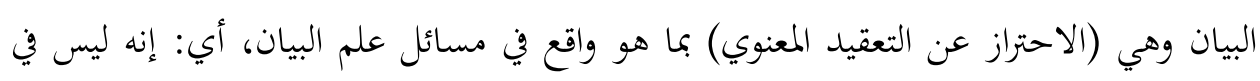
مباحث علم البيان ما يحترز به عن التعقيد المعنوي، وقد سبقه إلى ذلك ابن يعقوب المغربي، عندما ناقش هذا التعريف حول الوظيفة. وإذاكان البديل الذي اقترحه في تعريف علم البيان لتحقيق هذه الوظيفة، هو: دراسة النها

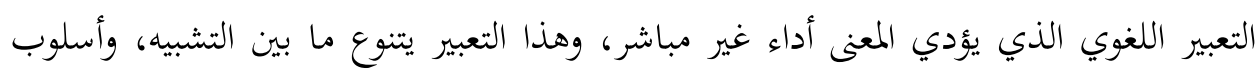

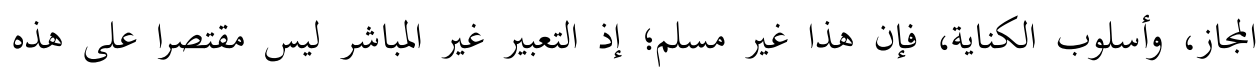
الأساليب التي ذكرها؛ فقد نص عبد القاهر نفسه على أننا في دقائق وأسرار، طريق العلم بها

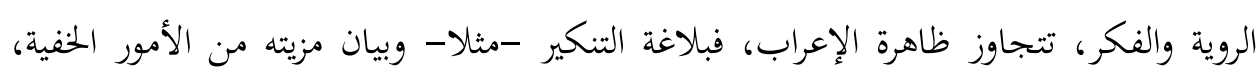

$$
\text { 2- 1- التعبير البياني، ص25 صنظر ص200. من هذا البحث. }
$$


والمعاني الروحانية(1)، وهذا دليل على أنه غير مباشر؛ بل إن الخروج عن مقتضى الظاهر، والمعاني المستفادة بمعونة القرائن -وهما من مباحث علم المعاني- صورتان من الصور غير المباشرة.

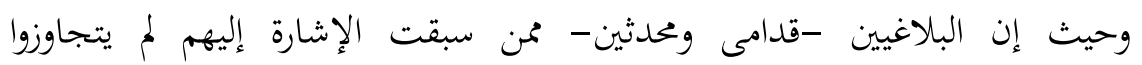

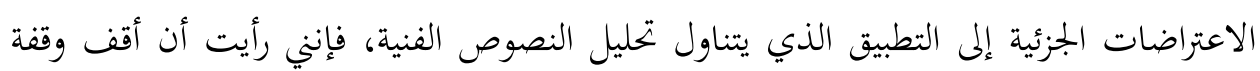
متأنية عند فكرة إيراد المعنى الواحد بطرق مختلفة من خلال عرض إنى أنموذجين من القرآن الكريم.

$$
\text { الأنموذج الأول: (أسلوب التشبيه): }
$$

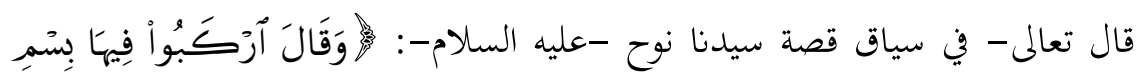

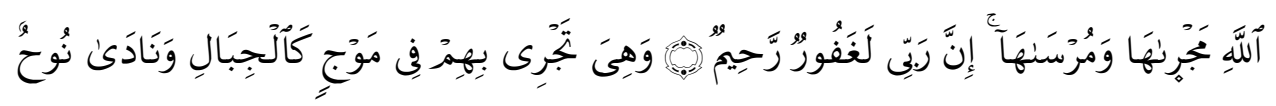

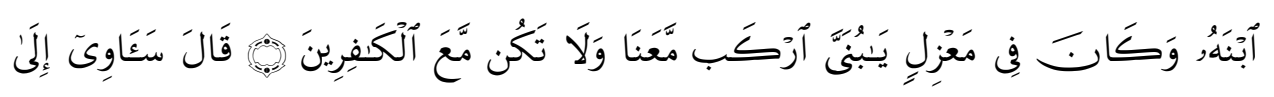

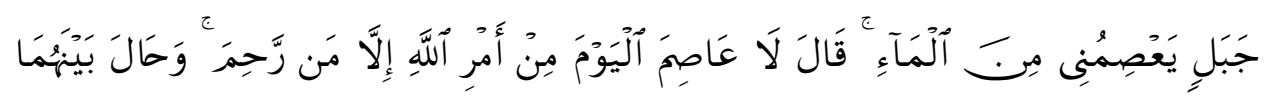

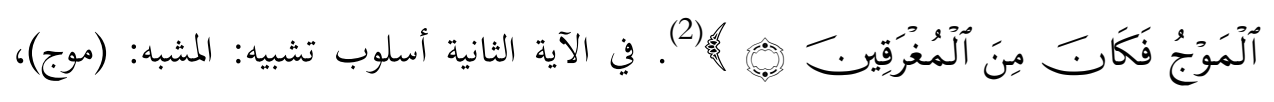
والمشبه به: (الجبال)، والأداة: (الكاف) ووجه الشبه محذوف، فالتشبيه مفرد مرسل مجمل صريح، غير تمثيلي. وقبل أن أحلل الآية أتساءل: إذا كان المجاز أبلغ من الحقيقة(3)، وإذا كان التشبيه ليس

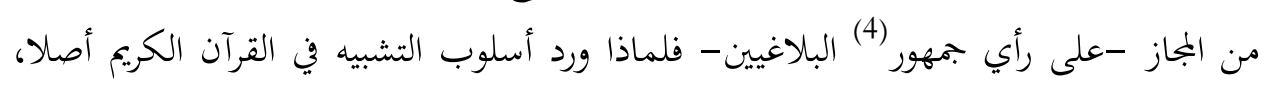
وهو ذروة البلاغة؟ وإذا كان التشبيه الغريب البعيد يكون في المركب بعامة، وفي (التمثيل) بخاصة،

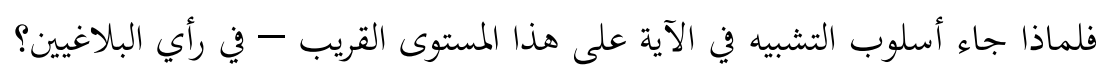

$$
\begin{aligned}
& \text { 1- 1 ينظر دلائل الإعجاز، ص547. }
\end{aligned}
$$

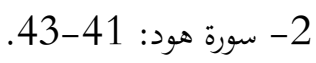

$$
\begin{aligned}
& \text { 3- 2 دلائل الإعجاز : صورد: }
\end{aligned}
$$

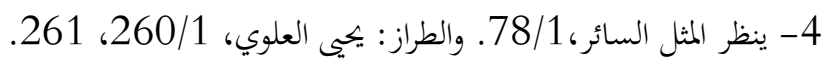


ولإججابة عن هذين التساؤلين أحلل الآية بما يأذن الله لي من الرفد والعون؛ إنه ولي

ذلك والقادر عليه.

إن الآية وردت في سياق تصوير حدث عظيم هو: (الطوفان) الذي أغرق الله به من كفر من قوم نوح -عليه السلام- وما فيه من دلالة على قدرة الله في هذا الكون، وأنه-وحده-

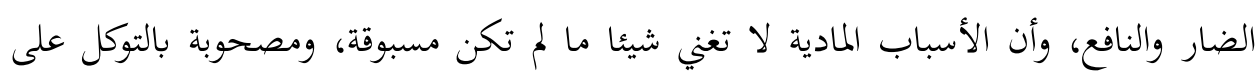

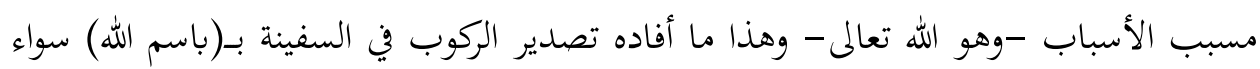

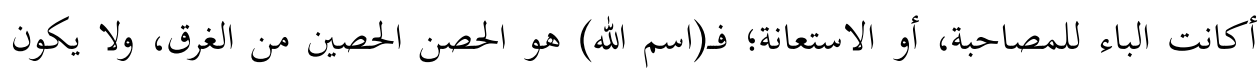
ذلك إلا لمن آمن به، وتوكل عليه، وتبرأ من الحول والقوة إلا به، وفي تقديم الظرف (باسم الله)

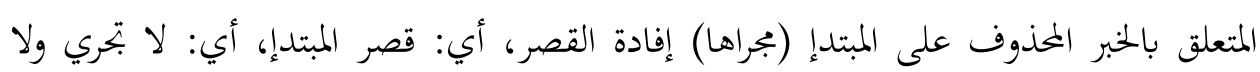

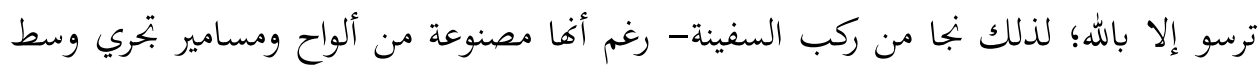

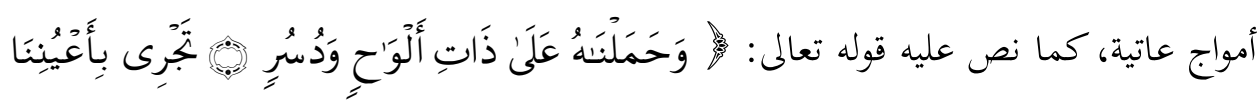

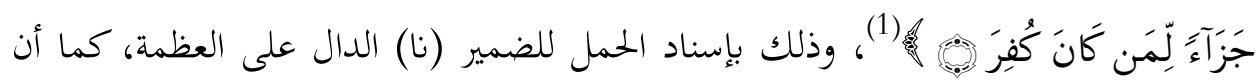
الجري محفوف برعاية الله وحفظه الذي دل عليه متعلق الفعل (تحري) المضاف إلى ضمير العظمة (نا)؛ فالأمر بصنع السفينة، ثم بركوب من آمن، توجيه للأخذ بالأسباب، واصطحاب اسم الله، الله

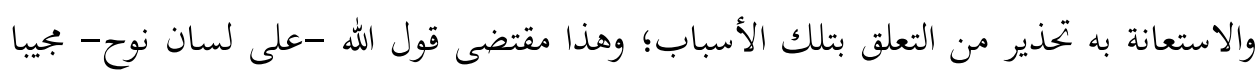

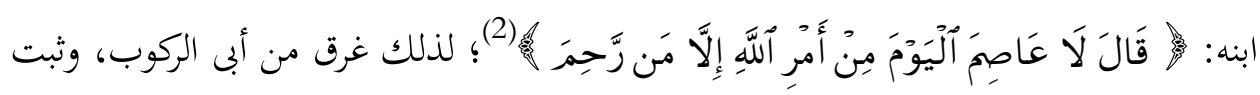
على الكفر، وآوى إلى جبل من شأنه الرسوخ والثبات، ظن أنه يعصمه من الماء؛ إذ لو كانت

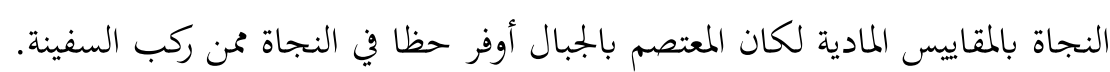
ولإدراك قيمة أسلوبٍ ما في سياقه لا بد من وضعه في مقابل أسلوب آخر مفترض،

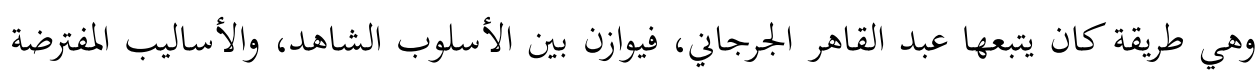


في الذهن مما يمكن أن يجل محل الشاهد، ثم يشرك القارئ معه في حكمه على أحدها بالتميز،

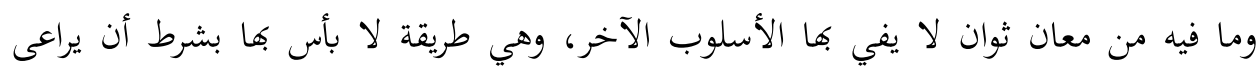
الموقف كله.

وحيث إن الآية تمثل أسلوبا من أساليب التشبيه وهو: (مفرد، مجمل، مرسل)، فإن

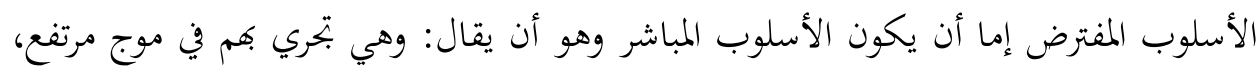

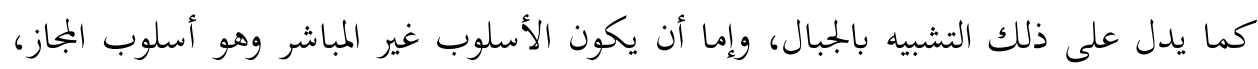

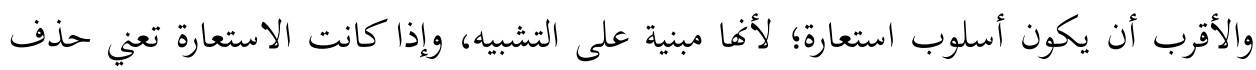

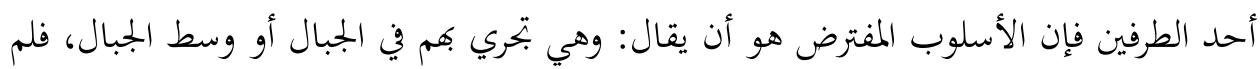

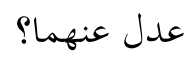

إن في اختيار التشبيه من الإيحاءات المناسبة للمقام (تصوير عظمة الطوفان الدالة على

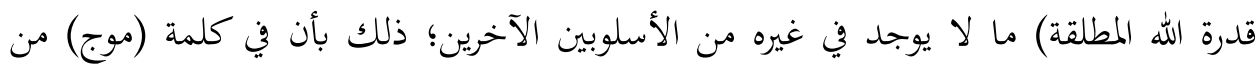

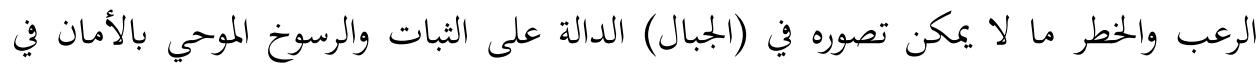

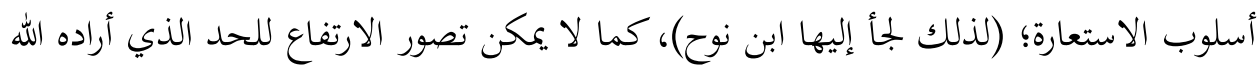

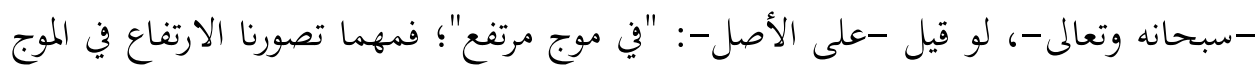

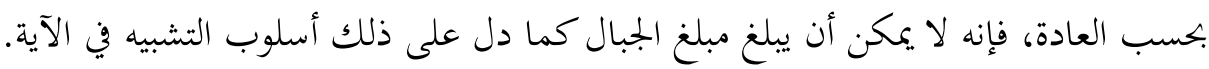

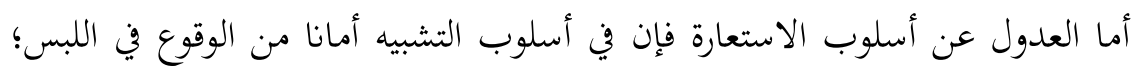

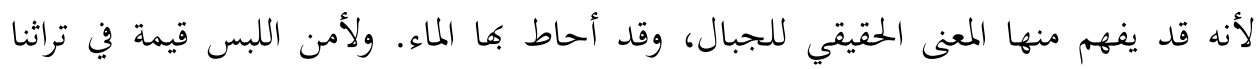
البلاغي؛ فقد برر عبد القاهر الجرجاني اختيار النابغة الذبياني لأسلوب التشبيه في أبياته المشهورة

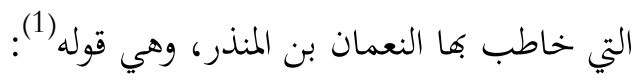

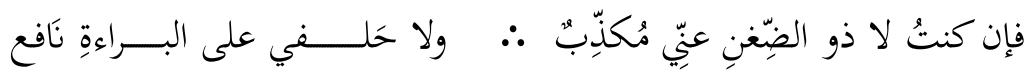

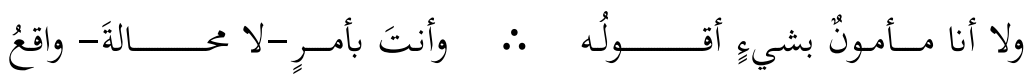

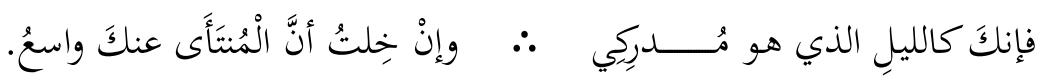

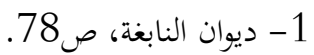


قائلا -موضحا الفرق بين الأسلوبين، وأن التشبيه يقدم أحيانا على الاستعارة؛ لأن في

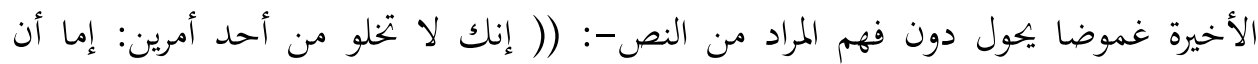
تحذف الصفة وتقتصر على ذكر (الليل) مجردا فتقول: "إن فررت أظلني الليل"، وهذا محال؛ لأنه

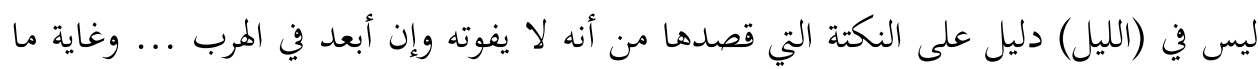

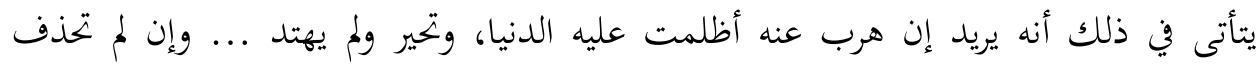

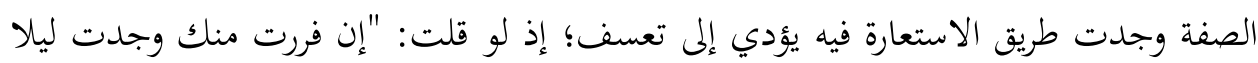

يدركني، وإن ظنتت أن المنتأى واسع" قلت ما لا تقبله الطباع )(1). إن حرص البلاغيين على تحقق التواصل بين المرسل والمرسل إليه، دعا عبد القاهر إلى النص صراحة على عدم الجواز في الانتقال من التشبيه إلى الاستعارة إلا (( إذا كان الشبه بين إنين

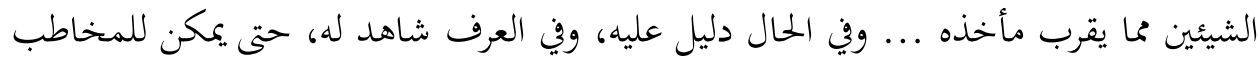
إذا أطلقت له الاسم أن يعرف الغرض ... إذ يعلم إذا قلت: "رأيت أسدا" -وأنت تريد

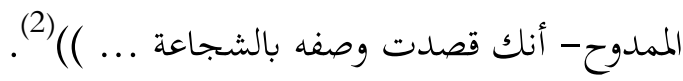
ومعنى تعذر تحول التشبيه إلى استعارة أنه يفوت الغرض المسوق له الكلام، وليس

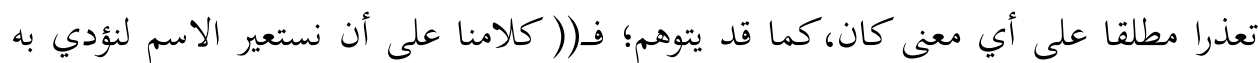

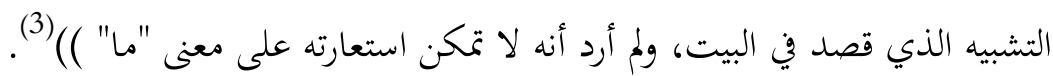

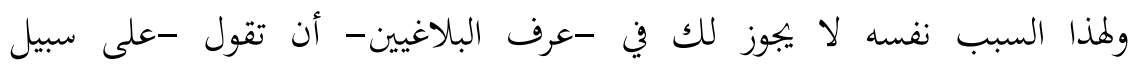
الاستعارة-: "رأيت أسدا"، وتريد إنسانا أبخر، وعلى سبيل الاستعارة التمثيلية: "رأيت إبلا مائة

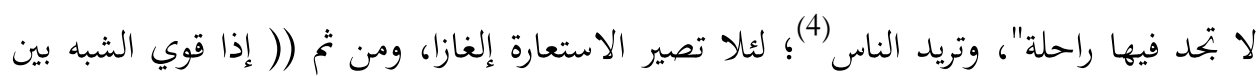
1-أسرار البلاغة: عبد القاهر الجرجاني، تح: علي رمضان الجربي، منشورات ELGA، فاليتا-مالطا،

$$
\text { 2- 2001 السابق: ص4، ص462. }
$$

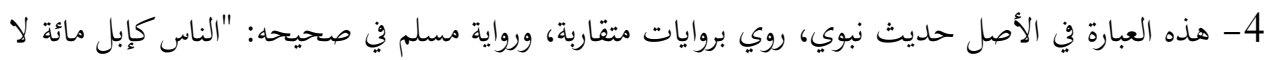
يجد الرجل فيها راحلة" النووي، شرح صحيح مسلم، كتاب فضائل الصحابة، رقم (2547)، 
الطرفين حتى اتحدا كالعلم والنور، والشبهة والظلمة، لم يحسن التشبيه وتعينت الاستعارة؛ لئلا يصير كتشبيه الشيء بنفسه ()(1) ويستشكل سعد الدين التفتازاني ما سبق ذكره في حسن الاستعارة، المبنية على جهات الحسن في التشبيه، ومن بينها: أن يكون وجه الشبه بعيدا غير مبتذل، واشتراط جلائه في الاستعارة ينافي ذلك، ويجيب عنه بأنه: (( يجب أن يكون من الجلاء بحيث لا يصير إلغازا، ومن الغرابة بحيث لا يصير مبتذلا ()(2). لكن قوة الشبه بين الطرفين ليست هي المبرر الوحيد في اختيار الاستعارة؛ فقد تحسن الاستعارة لعلة خاصة ببناء الصورة الفنية؛ ففي سياق الفرق بين التشبيه والاستعارة في بعض النماذج المتشاهة شكلا يحتكم عبد القاهر إلى الموازنة بين (الأصل) و(العدول) عنه؛ ليريك أن الأصل، أي: أصل الاستعارة، وهو (التشبيه) -وإن كان مما يتكلم به- مرذول، أو فيه غثاثة وركاكة؛ بل ذهب إلى أن ثمة تفاوتا بين غثاثة وأخرى؛ فإذا كان إظهار التشبيه في بيت الوأواء

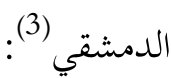

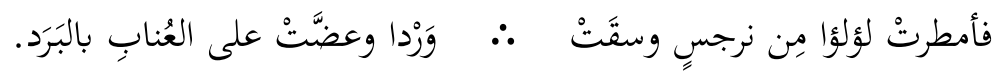
أن يقال: فأمطرت دمعا كأنه اللؤلؤ ... لا يحسن، ويذهب بالأريحية التي تجدها في

العدول عن التشبيه إلى الاستعارة، فإن إظهار التشبيه في مثل قول ابن المعتز (4):

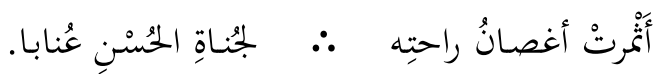

$$
\begin{aligned}
& \text { 1- ينظر شروح التلخيص 224/4-229. }
\end{aligned}
$$

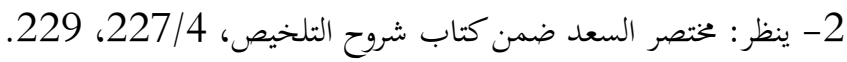

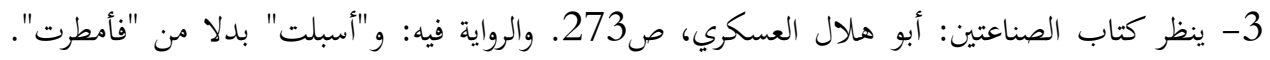

$$
\begin{aligned}
& \text { والبيت من التشبيه عند أبي هلال العسكري، وهو خطأ. } \\
& \text { 4- ويوان ابن المعتز، ص14. }
\end{aligned}
$$


يقبح قبحا مفرطا: (( ألا ترى أنك لو حملت نفسك على أن تظهر التشبيه، وتفصح به، احتجت إلى أن يقول: أثرت أصابع يده، التي هي كالأغصان، لطالبي الحسن شبيه العناب

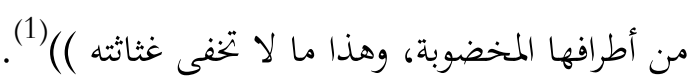
الأنموذج الثاني: (أسلوب الاستعارة).

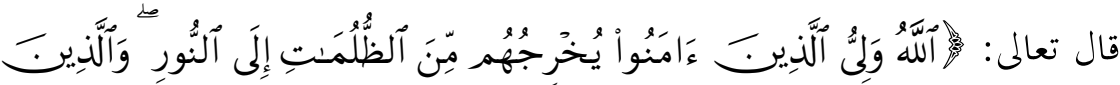

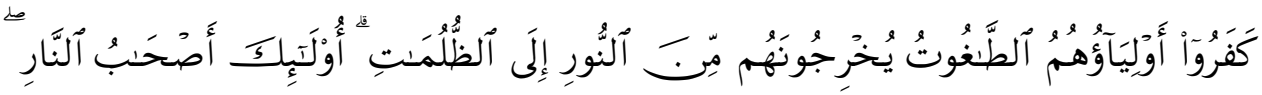

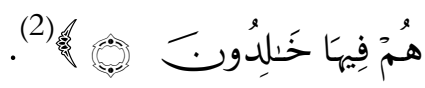
في هذه الآية القرآنية الكريمة استعارتان بينهما مطابقة في المعنيين الحقيقي والبمازي؛ فلمراد بالظمات: الكفر، وبالنور: الإيمان، ولو قيل على الأصل: "يخرجمم من الكفر إلى الإيمان"، لافتقد الأسلوب ما تدل عليه اللفظة المستعارة (الظلمات) للكفر من التخبط والحيرة، وعدم الاهتداء إلى الطريق الصحيح الموصل إلى الغرض، ولافتقد ما تدل عليه كلمة (النور)

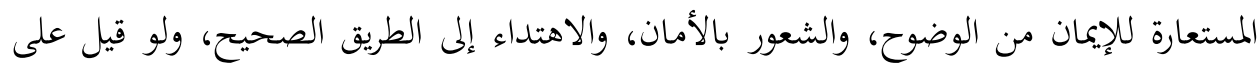

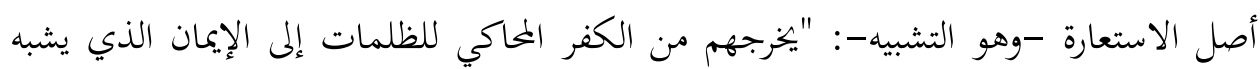
النور" لجاء الأسلوب غثا ثقيلا بادي التكلف، لا لشيء إلا لقوة العلاقة بين الطرفي؛؛ لذلك

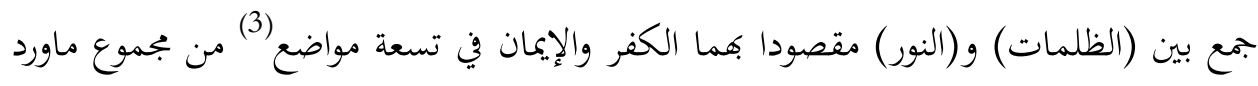

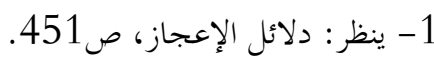

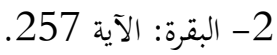
3- هي في المواضع التالية: سورة البقرة: 257 مرتئني، سورة المائدة: 16، سورة الأنعام: 122، سورة إبراهيم:

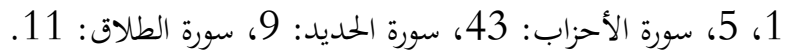


بجازا، على سبيل القطع، وهو أربعة وعشرون موضعا(1)، وجمع بينهما في موضعين(2) على سبيل التشبيه الضمني الذي هو أقرب إلى الاستعارة من حيث إن بنية المشبه به مفصولة نحويا عن بنية المشبه، والدليل على ذلك اختلاف العلماء في مثل هذه التراكيب لا سيما إذا بعد الممثل له كما في الآية (20) من سورة فاطر؛ فهي -على رأي من يرى أفها تشبيه ضمني- ترجع إلى الآية:

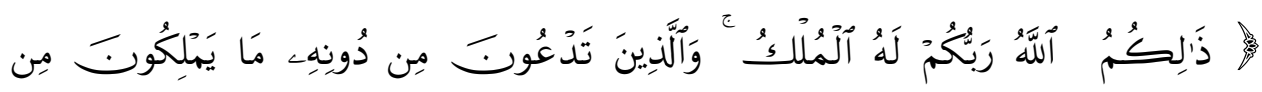
قِطمِيرِ أما ما ورد من كلمة (نور) مشبها به على سبيل التصريح، والمشبه (الكتاب) أو

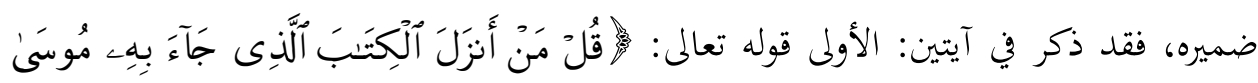

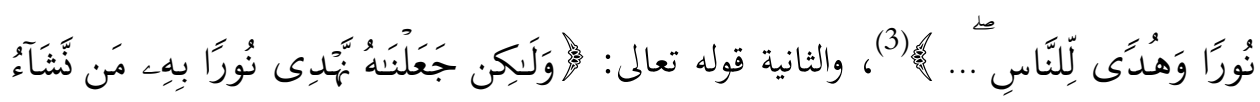

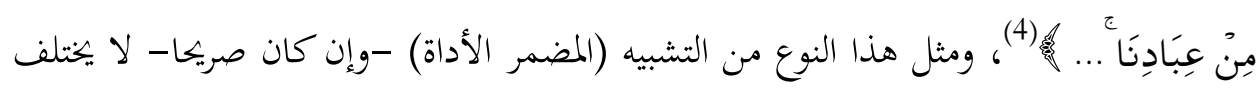
عن التشبيه الضمني في قربه من الاستعارة؛ للعلاقة غير الطبيعية بين المشبه، والمشبه به، بسبب اختلاف جنسيهما، ولقبح تقدير الأداة؛ فلو قيل: "من أنزل الكتاب الذي جاء به موسى كنور"

1- هي في المواضع الآتية: سورة النساء: 174، سورة المائدة: 15، 44، 46، سورة الأعراف: 157، 157، سورة

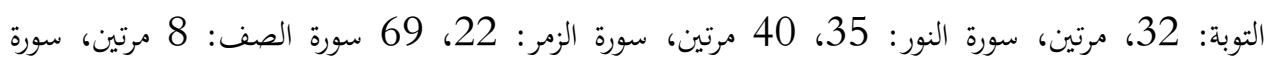
التغابن: 8.

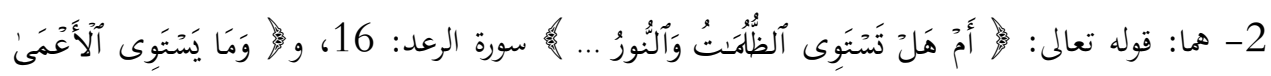

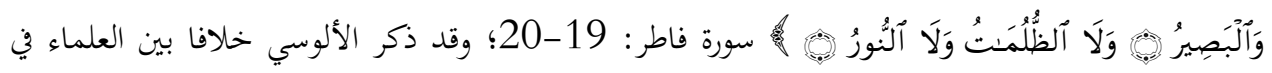

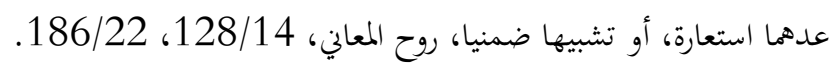
3- سورة الأنعام: 91. 4- 20 سورة الشورى: 52. 
و"جعلناه كنور" لم يحسن، شأهما -وإن اختلفا إعرابا(1)- شأن قولنا: "لعُمَّم أسد"؛ ولهذا السبب

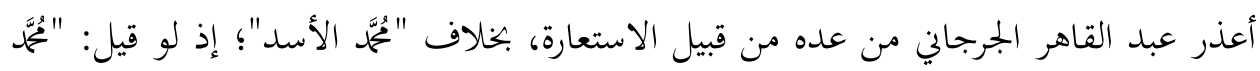
كالأسد" لم يقبح؛ ولذلك لا يعد استعارة(2). وأما بقية المواضع المجازية فإِها مستعارة لما له علاقة بالإيمان؛ (( فقد استعار الله -عز

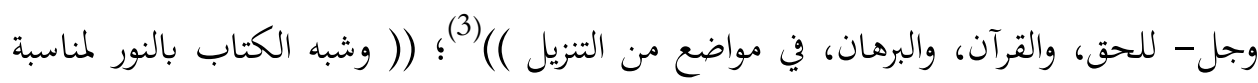
الهدي به؛ لأن الإيمان والهدى والعلم تشبه بالنور، والضلال والجهل والكفر تشبه بالظلمة، قال

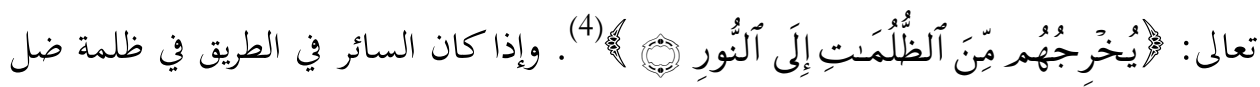
عن الطريق، فإذا استنار له اهتدى إلى الطريق، فالنور وسيلة الاهتداء )(5).

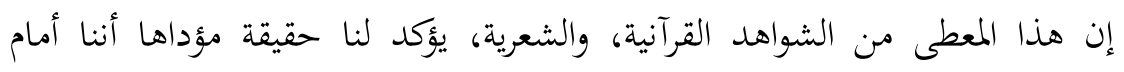
مجموعة من العلاقات المتشابكة، وتركيبات أسلوبية يتعذر حصرها، وسياقات تند عن التحديد، حتى إذا برز التركيب في صورته الفنية ذات الصلة الوثيقة بالمتكلم والسياق، والمتلقي، وبالمكونات الأسلوبية الأخرى، كشف عن السطحية التي تقتضيها فكرة إيراد المعنى الواحد بطرق مختلفة في الوضوح؛ إذ لو كان الأمر كذلك لانتفت الفروق بين الأساليب، وما انماز أسلوب من أسلوب،

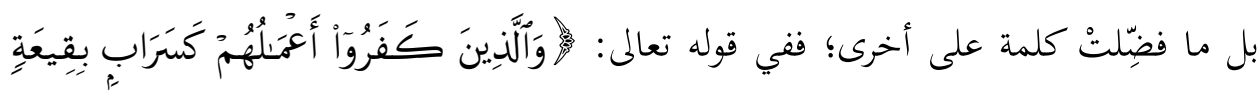

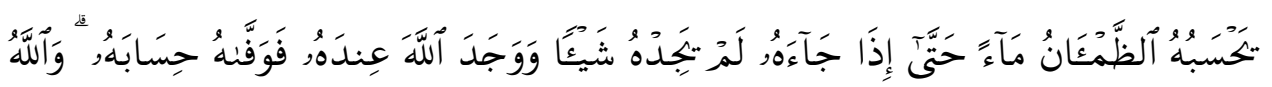

1- إعراب "نورا" الأولى حال: إما من "الكتاب"، والعامل "أنزل"، وإما من الضمير في "به"، والعامل "جاء".

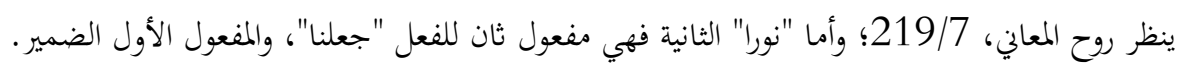

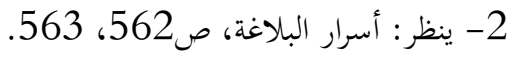

$$
\begin{aligned}
& \text { 3- الكشاف، 2323/5 } \\
& \text { 4- سورة البقرة: } 257 . \\
& \text { 5- التحرير والتنوير، 154/25. ستورة الترة }
\end{aligned}
$$




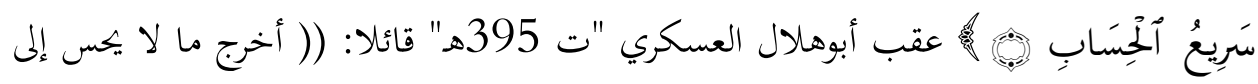
ما يحس، والمعنى الذي يجمعهما بطلان المتوهم مع شدة الحاجة وعظم الفاقة، ولو قال يحسبه الرائي ماء لم يقع موقع قوله (الظمآن)؛ لأن الظمآن أشد فاقة إليه وأعظم حرصا عليه )(1). وإذا كانت ملاحظة العسكري السابقة متعلقة بالرسالة فإن عبد القاهر الجرجاني

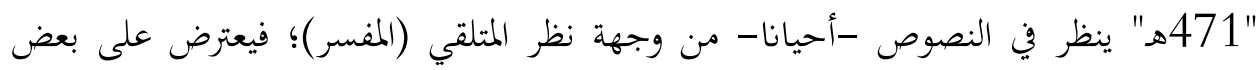

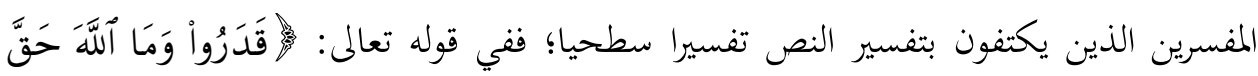

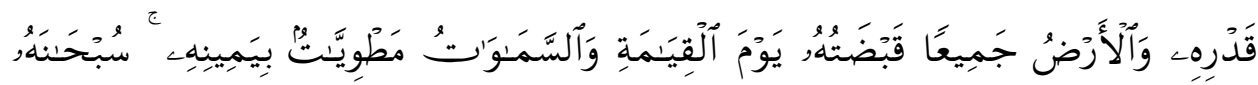

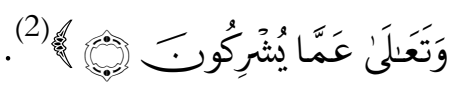
لا يرضى عبد القاهر بتفسير (القبضة)، و(اليمين) بالقدرة، أي: المجاز المرسل الذي علاقته المحلية، ورأى أن (( هذا منهم تفسير على الجملة، وقصد إلى نفي الجارحة بسرعة؛ خوفا

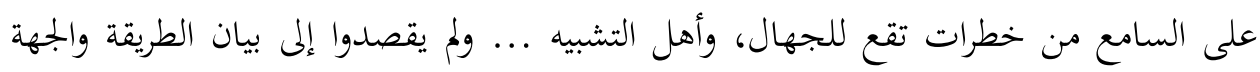

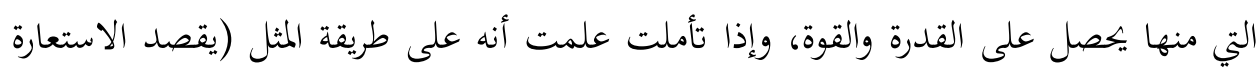

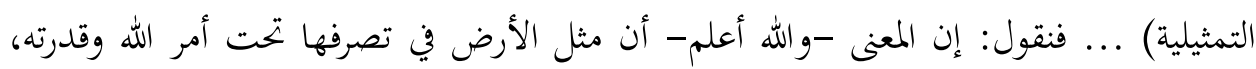

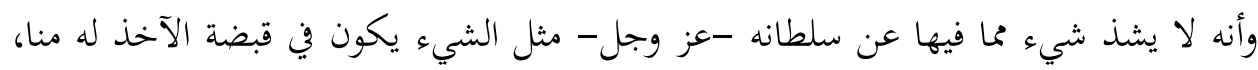

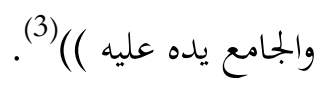

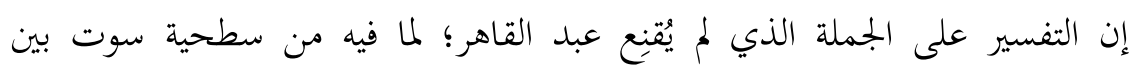

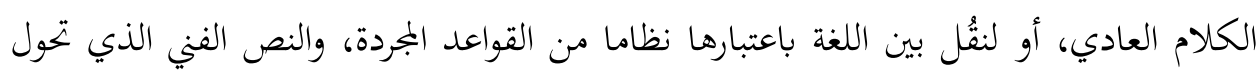

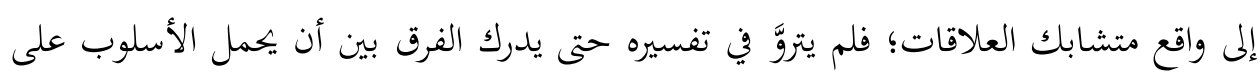

$$
\text { 3- 1- سورة الزمر: 67 67 الصناعتين: ص262. }
$$


مفهوم المجاز المرسل، وبين أن يحمل على الاستعارة التمثيلية، كما في تفسير عبد القاهر المبني على الفكر والروية، حتى ينال النص حقه، دليل على أن لغة الأسلوب، لا تقبل مثل هذا التناول السطحي، وإن قبله أسلوب اللغة.

إن مثل هذه النظرات العجلى - كما وصفها عبد القاهر - كانت -في اعتقادي- وراء

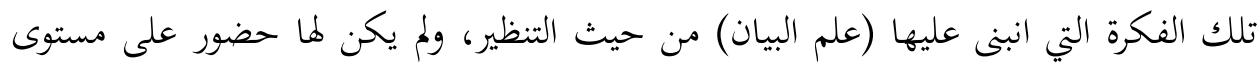

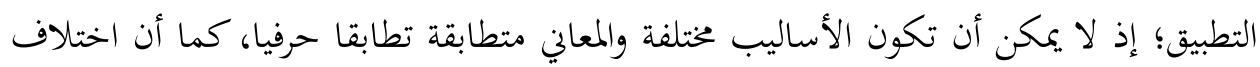
الوضوح ليس منضبطا بالصورة التي تبدو من خلال شراح التلخيص، والمتمثلة في أن التشبيه

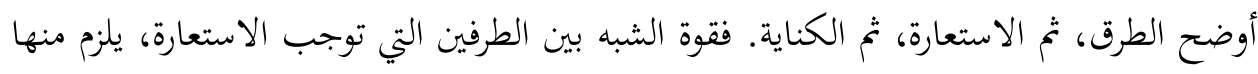
أن تكون الاستعارة أوضح من التشبيه المركب الذي يمتاج إلى مزيد من التأمل لاستنباط وجه الشبه، كما سبق في آية النور، فضلا عن أن بعض الأساليب يتعذر أن تحل محل أسلوب آنسية آخر، والدليل على ذلك أن البلاغيين المتأخرين الذين مثلوا للطرق المختلفة في الوضوح لم يمثلوا بالمجاز المرسل، أو الاستعارة التمثيلية.

\section{الحاتمة:}

$$
\text { محا سبق عرضه ظهر لي ما يأتي: }
$$

- أن تقسيم السكاكي البلاغة وما ترتب عليه من تصنيف للعلوم، وتعريف كل علم، لم يكن محل قبول حتى ممن اقتفى أثره من العلماء البلاغيين الذين عرفوا بشراح التلخيص. - لم يتجاوزوا في رفضهم الاعتراضات الجزئية إلى تصور بديل، باستثناء سعد الدِّين التفتازاني الذي اقترح بديلا لتعريف علم البيان يتطابق ومحتوياته. - خلت اعتراضاقم -لا سيما فيما يخص فكرة إيراد المعنى الواحد بطرق مختلفة- من الشواهد التي تؤيد اعتراضاهم. 
- أن شفيع السيد الذي ناقش ما في التعريف من هنات -وهو من البلاغيين

المحدثين- وقع في الخظظور نفسه؛ فلم يدعم اعتراضاته بالشواهد اللازمة، ولم يسلم تعريفه من سن القصور. - مار.

- أن فكرة إيراد المعنى الواحد بطرق غختلفة تتناقض وما حكم به البلاغيون أنفسهم من

إيجاب طريق التشبيه تارة، إذا تعذر فهم المعنى المراد بطريق الاستعارة، وقبحه تارة أخرى إذا قويت العلاقة بين الطرفين؛ لما فيه من شبه تشبيه الشيء بنفسه.

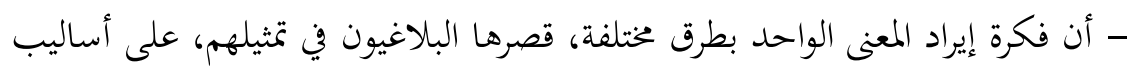
التشبيه، والاستعارة، والكناية، رغم أخا أمثلة مصطنعة، بعيدة عن لغة الأدب، دون المجاز المرسل، والاستعارة التمثيلية، وكأفم لم ميجدوا فيهما مسوغا مقبولا للدلالة على معنى الكرم.

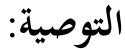

بناء على المقدمات والنتائج التي سبق طرحها أوصي بما يأتي: - إعادة النظر في تقسيم السكاكي علوم البلاغة، وذلك بالنظر إلى أنها علم واحد

$$
\text { يمكن أن نسي له مصطلح (علم البيان). }
$$

- إعادة النظر في تعريف هذا المصطلح بالنظر إلى ميدانه، وهو الكلام البليغ -أولا-

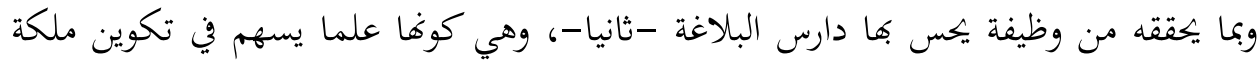
نقدية أكثر من كونه علما يسهم في تكوين ملكة إنشائية، أو أدبية، أو إبداعية.

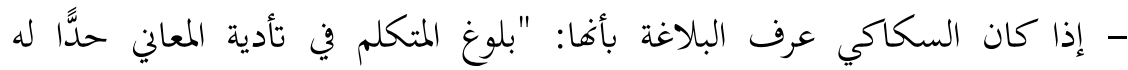
اختصاص بتوفية خواص التراكيب حقها، وإيراد أنواع التشبيه والمجاز والكناية على وجهها، فإنها يمكن تحديد (علم البيان) بأنه: علم يعنى بالفروق بين الأساليب على المستويين: الإفرادي

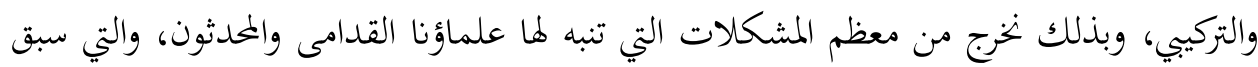
عرضها في هذا البحث. 


\section{المصادر والمراجع}

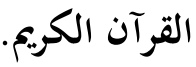

1- أسرار البلاغة: عبد القاهر الجرجاني، تح: علي رمضان الجربي، منشورات ELGA، فاليتا مالطا، 2001م. 2- الإيضاح: الخطيب القزويني، قدم له وبوبه وشرحه: علي بو ملحم، دار ومكتبة الهلال،

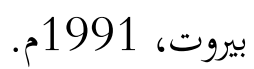
3- البلاغة التطبيقية، دراسة تحليلية لعلم البيان: ثُحَّهَ رمضان الجربي، منشورات جامعة ناصر،

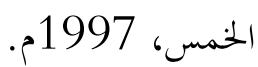

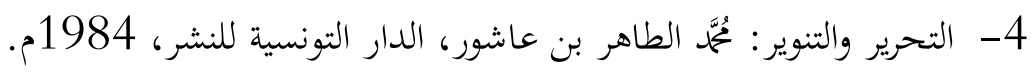

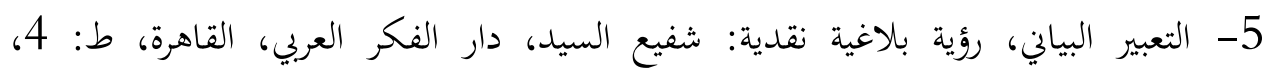
1415هـ-1995م الكيان،

6- الجامع الصحيح المختصر: ثُمَّمَ بن إسماعيل أبو عبد الله البخاري الجعفي، قام بشرحه

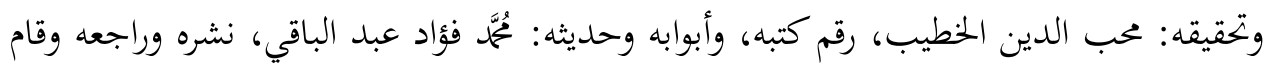
بإخراجه، وأشرف على طبعه قصي محب الدين الخطيب، المطبعة السلفية، ومكتبتها القاهرة، "د. 7- دلائل الإعجاز: عبد القاهر الجرجاني، قرأه وعلق عليه: محمود شاكر، دار المدني، بجدة،

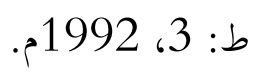
8- ديوان العباس بن الأحنف، شرح: أنطوان نعيمة، دار الجيل، بيروت، ط: 1، 1416هـ 1995م. 9- ديوان امرئ القيس، اعتنى به وشرحه: عبد الرحمن المصطاوي، دار المعرفة، بيروت، لبنان، ط: 2، 1425هـ- 2004م. 10- ديوان ابن المعتز، فسر غريبه: محيي الدين الحياط، دار الإقبال، "د. تـ". 
11- ديوان النابغة، اعتنى به: حمدو طماس، دار المعرفة، بيروت، لبنان، ط: 2، 1426هـ2005

12- روح المعاني في تفسير القرآن العظيم والسبع المثاني: شهاب الدين محمود بن عبد الله الحسيني الألوسي، دار إحياء التراث العربي، بيروت، لبنان، "د.ت" 13- سر الفصاحة: ابن سنان الخفاجي، شرح وتصحيح: عبد المتعال الصعيدي، مكتبة

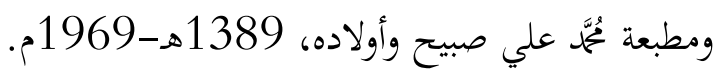
14- شرح ديوان الحماسة: المرزوقي، نشره: أحمد أمين، وعبد السلام هارون، دار دار الجيل،

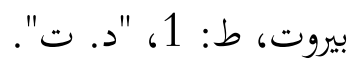
15- شرح صحيح مسلم: النووي، دار الخير، بيروت، ط: 5، 1420هـ-1999م. 16- شروح التلخيص مع حاشية الدسوقي على شرح السعد: سعد الدين التفتازاني، وابن

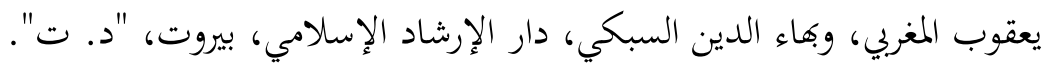

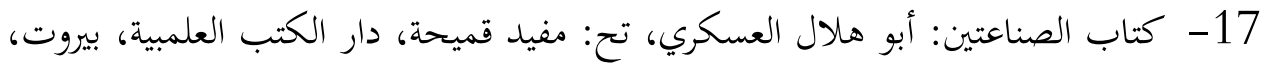
لبنان، ط: 2، 1404 148ـ 1984م. 18- الكشاف: الزخشري، تحقيق وتعليق ودراسة: عادل أحمد عبد الموجود، وآخرون، مكتبة

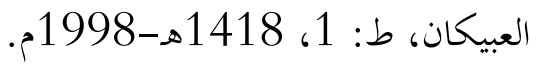
19- المثل السائر في أدب الكاتب والشاعر: ضياء الدين بن الأثير، تح: عُمَّه محي الدِّين

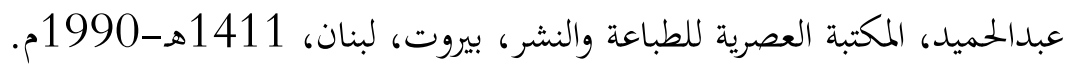
20- المطول في شرح تلخيص المفتاح: سعد الدين مسعود بن عمر التفتازاني، نشر المكتبة

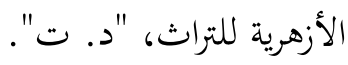
21- مغني اللبيب عن كتب الأعاريب: ابن هشام الأنصاري تح: مازن المبارك، وهُمَّمَ على حمد

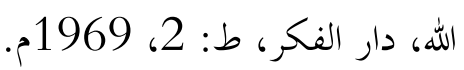
22- مفتاح العلوم: أبويعقوب يوسف بن يُمَّمَ بن علي السكاكي، تح: عبد الحميد هنداوي،

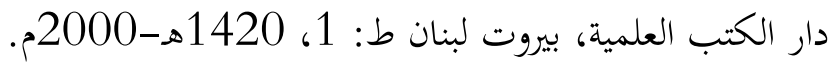

